\title{
Strato-mesospheric CIO observations by SMILES: error analysis and diurnal variation
}

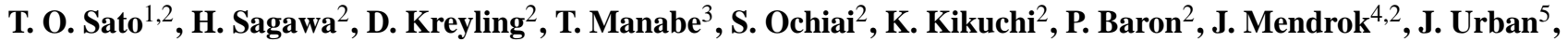 \\ D. Murtagh ${ }^{5}$, M. Yasui ${ }^{2}$, and Y. Kasai ${ }^{2,1}$ \\ ${ }^{1}$ Tokyo Institute of Technology, 4259 Nagatsuta-cho, Midori-ku, Yokohama, Kanagawa 226-8503, Japan \\ ${ }^{2}$ National Institute of Information and Communications Technology, 4-2-1 Nukui-kitamachi, Koganei, \\ Tokyo 184-8795, Japan \\ ${ }^{3}$ Osaka Prefecture University, 1-1 Gakuen-cho, Naka-ku, Sakai, Osaka 599-8531, Japan \\ ${ }^{4}$ Luleå University of Technology, P.O. Box 812, 98128 Kiruna, Sweden \\ ${ }^{5}$ Chalmers University of Technology, Department of Earth and Space Sciences, 41296 Gothenburg, Sweden
}

Correspondence to: T. O. Sato (sato.t.ak@m.titech.ac.jp)

Received: 24 May 2012 - Published in Atmos. Meas. Tech. Discuss.: 4 July 2012

Revised: 18 October 2012 - Accepted: 19 October 2012 - Published: 20 November 2012

\begin{abstract}
Chlorine monoxide $(\mathrm{ClO})$ is the key species for anthropogenic ozone losses in the middle atmosphere. We observed $\mathrm{ClO}$ diurnal variations using the Superconducting Submillimeter-Wave Limb-Emission Sounder (SMILES) on the International Space Station, which has a non-sunsynchronous orbit. This includes the first global observations of the $\mathrm{ClO}$ diurnal variation from the stratosphere up to the mesosphere. The observation of mesospheric $\mathrm{ClO}$ was possible due to 10-20 times better signal-to-noise $(\mathrm{S} / \mathrm{N})$ ratio of the spectra than those of past or ongoing microwave/submillimeter-wave limb-emission sounders. We performed a quantitative error analysis for the strato- and mesospheric $\mathrm{ClO}$ from the Level-2 research (L2r) product version 2.1.5 taking into account all possible contributions of errors, i.e. errors due to spectrum noise, smoothing, and uncertainties in radiative transfer model and instrument functions. The SMILES L2r v2.1.5 ClO data are useful over the range from 0.01 and $100 \mathrm{hPa}$ with a total error estimate of 10-30 pptv (about 10\%) with averaging 100 profiles. The SMILES ClO vertical resolution is 3$5 \mathrm{~km}$ and $5-8 \mathrm{~km}$ for the stratosphere and mesosphere, respectively. The SMILES observations reproduced the diurnal variation of stratospheric $\mathrm{ClO}$, with peak values at midday, observed previously by the Microwave Limb Sounder on the Upper Atmosphere Research Satellite (UARS/MLS). Mesospheric $\mathrm{ClO}$ demonstrated an opposite diurnal behavior, with nighttime values being larger than daytime values. A
\end{abstract}

$\mathrm{ClO}$ enhancement of about $100 \mathrm{pptv}$ was observed at 0.02 to $0.01 \mathrm{hPa}$ (about $70-80 \mathrm{~km}$ ) for $50^{\circ} \mathrm{N}-65^{\circ} \mathrm{N}$ from JanuaryFebruary 2010. The performance of SMILES ClO observations opens up new opportunities to investigate $\mathrm{ClO}$ up to the mesopause.

\section{Introduction}

Chlorine monoxide $(\mathrm{ClO})$ is a primary form of reactive chlorine and a key intermediate for ozone losses. The partitioning of the reactive and reservoir forms of the halogen species modulates the destruction of ozone. Chemical ozone losses are mostly controlled by spatio-temporal distributions of active halogens. For example, $\mathrm{ClO}$ activation on surfaces of polar stratospheric cloud due to low temperatures produced the strong Arctic ozone depletion during the winter of 2010/2011 (Manney et al., 2011). Microwave spectroscopic remote sensing from space is one of the best methods of obtaining global $\mathrm{ClO}$ distributions in the Earth's middle atmosphere. There have been four satellite instruments so far that enable the $\mathrm{ClO}$ global distributions to be observed. The first satellite observation of $\mathrm{ClO}$ was accomplished by the $\mathrm{Mi}$ crowave Limb Sounder (MLS) on board the Upper Atmosphere Research Satellite (UARS), which was launched by NASA in 1991 (Waters et al., 1993); the UARS/MLS measured the $\mathrm{ClO}$ transition at $204.4 \mathrm{GHz}$. The Sub-Millimetre 


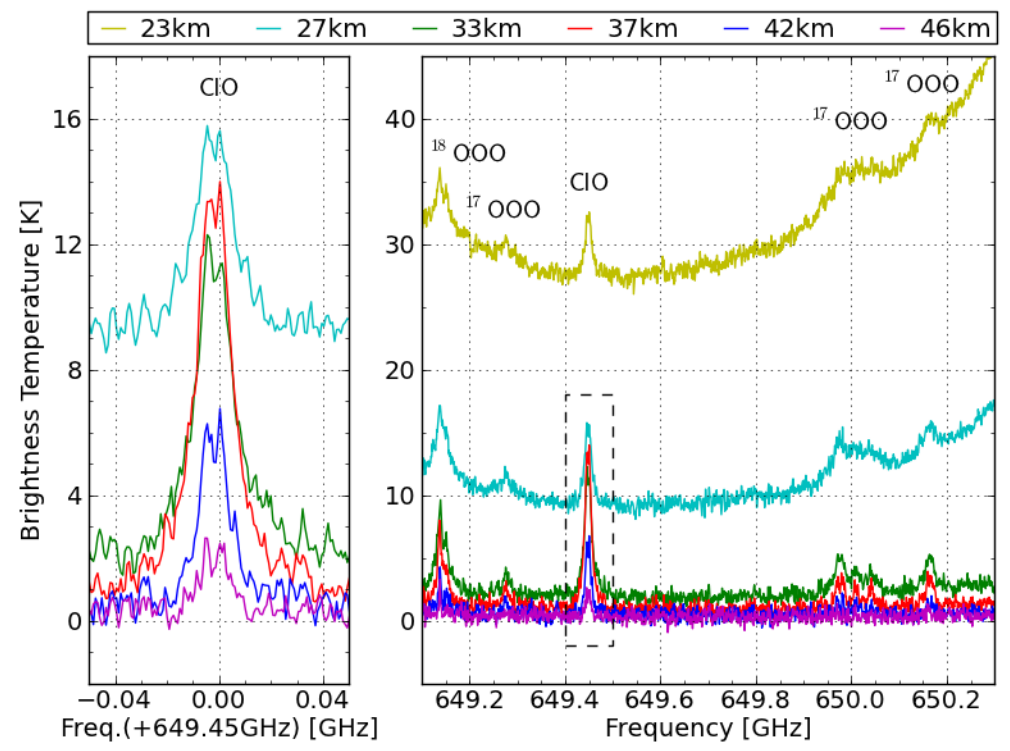

Fig. 1. Single-scan Band C spectra observed by SMILES at tangent heights of 23, 27, 33, 37, 42 and $46 \mathrm{~km}$. The frequency is calibrated by considering Doppler shift. The figure at left is a magnification of the $\mathrm{ClO}$ transitions at 649.445 and $649.451 \mathrm{GHz}$. The figure at right shows the full frequency region for Band C. Date: 9 November 2009. LT (local time): 00:22. Latitude: $57.2^{\circ}$ N. Longitude: $6.4^{\circ}$ E.

Radiometer on board the Odin satellite (Odin/SMR) was launched in February 2001 and has been observing $\mathrm{ClO}$ using the transition at $501.3 \mathrm{GHz}$ (Murtagh et al., 2002). Aura/MLS was launched in 2004 and has been observing $\mathrm{ClO}$ using the transition at $649.4 \mathrm{GHz}$ (Waters et al., 2006). The Superconducting Submillimeter-Wave Limb-Emission Sounder (SMILES) also observed $\mathrm{ClO}$ using the same transition as Aura/MLS but with much more sensitive technology. SMILES made observations from the Japanese Experiment Module (JEM) of the International Space Station (ISS) between 12 October 2009 and 21 April 2010 (Kikuchi et al., 2010).

The SMILES observations were notable in that they were (1) the first passive observations of the Earth's atmosphere with a sensitive 4-K submillimeter-wave receiver and (2) the most sensitive observations of short-lived atmospheric species with diurnal variations, which were achieved by the non-sun-synchronous orbit of the ISS.

The SMILES instrument employs superconductorinsulator-superconductor (SIS) mixers cooled at about $4 \mathrm{~K}$ and high-electron-mobility-transistor (HEMT) amplifiers at 20 and $100 \mathrm{~K}$. The receiver system achieves a low system noise temperature $\left(T_{\text {sys }}\right)$ of about $350 \mathrm{~K}$ and a signal-to-noise $(\mathrm{S} / \mathrm{N})$ ratio of about 50 for stratospheric $\mathrm{ClO}$ at mid-latitudes for a single-scan spectrum. $T_{\text {sys }}$ achieved with receiver systems using conventional Schottky diodes is about 3000$6000 \mathrm{~K}$ in the $500-600 \mathrm{GHz}$ region for passive satellite observations. The SMILES target species are $\mathrm{O}_{3}, \mathrm{ClO}$, $\mathrm{H}^{35} \mathrm{Cl}, \mathrm{H}^{37} \mathrm{Cl}, \mathrm{O}_{3}$ isotopomers, $\mathrm{BrO}, \mathrm{HO}_{2}, \mathrm{HOCl}, \mathrm{CH}_{3} \mathrm{CN}$ and $\mathrm{HNO}_{3}$ in the stratosphere and the mesosphere, as well as $\mathrm{H}_{2} \mathrm{O}$ and ice clouds in the upper troposphere/lower stratosphere. SMILES has three observation frequency bands of Band A (624.32-625.52 GHz), Band B (625.12$626.32 \mathrm{GHz})$ and Band $\mathrm{C}(649.12-650.32 \mathrm{GHz})$. The $\mathrm{ClO}$ transitions observed by using SMILES in the ground rovibronic state ( $\Lambda$-type doubling, $J=35 / 2-33 / 2)$ are located at 649.445 and $649.451 \mathrm{GHz}$ in Band C (Fig. 1). Two of the three frequency bands were used simultaneously, as in simultaneous observations using Bands A and B, Bands B and $\mathrm{C}$, or Bands $\mathrm{C}$ and $\mathrm{A}$, since SMILES had two spectrometers. About $70 \%$ of all observations were for Band C. SMILES observed the Earth's limb from the JEM/ISS at an altitude of $330-370 \mathrm{~km}$. The latitudes covered by SMILES observations were normally $38^{\circ} \mathrm{S}-65^{\circ} \mathrm{N}$. About 1600 points were observed daily by SMILES. The SMILES antenna limb scans were normally performed from 0 to $100 \mathrm{~km}$.

We quantitatively evaluated a total error in the $\mathrm{ClO}$ observations taking into account all known contributions of errors, i.e. errors due to spectrum noise, smoothing, and uncertainties in radiative transfer model and instrument functions. An error due to inaccuracy in spectrum calibration was also evaluated. Uncertainties of the error contributions were conservatively determined based on the laboratory and in-orbit measurements made by the SMILES mission team for the Level-2 research (L2r) product version 2.1.5. Section 2 describes all error sources considered in this study and methods of calculating the errors in the SMILES ClO observations. In Sect. 3, we described results of the error analysis. Section 4 described diurnal variations observed by SMILES. Stratospheric $\mathrm{ClO}$ diurnal variations observed by SMILES were compared to those observed by UARS/MLS. Diurnal 
variations of the mesospheric $\mathrm{ClO}$ up to $80 \mathrm{~km}$ were observed by SMILES for the first time from space.

The retrieval algorithm of the L2r version 2.1.5 was optimized for the middle stratosphere up to the mesosphere. We focused on $\mathrm{ClO}$ in the middle stratosphere and the mesosphere at equator and mid-latitude regions. A polar enhanced $\mathrm{ClO}$ at lower stratosphere was not discussed in this paper. Several issues for retrieval in the lower stratosphere are planned to be improved in the next version of $\mathrm{L} 2 \mathrm{r}$ product.

\section{Method of characterizing error}

We have performed an error analysis for volume mixing ratio (VMR) profile of $\mathrm{ClO}$ using a single-scan spectrum. The error in the $\mathrm{ClO}$ profile resulted from spectrum statistics noise and also from inaccuracy in spectrum synthesis using forward model and spectrum calibration.

\subsection{Uncertainties in synthesized and observed spectra}

\subsubsection{Calculation of radiative transfer}

We used the Advanced Model for Atmospheric Terahertz Radiation Analysis and Simulation (AMATERASU) (Baron et al., 2008) for clear-sky radiative transfer calculations and instrument functions, which was also used for calculation of the L2r version 2.1.5 (Baron et al., 2011). The details on the forward model calculations are described by Urban et al. (2004). Radiance intensity at frequency $v$ is calculated using a total absorption coefficient $k_{\nu}$ :

$k_{v}(s)=\sum_{p, q} \rho^{p}(s) J_{v_{q}}^{q}(T) \frac{v}{v_{q}} f_{v}\left(v_{q}, w_{q}\right)+k_{v}^{\text {cont }}(s)$,

where $s$ is the line-of-sight, $\rho^{p}(s)$ is the number density of the species $p, v_{q}$ is the frequency of the transition $q, J_{v_{q}}^{q}(T)$ is the line intensity of the transition $q$ at the temperature $T$, $f_{v}\left(v_{q}, w_{q}\right)$ is the line shape function for the transition $q, w_{q}$ is the line width of the transition $q$ and $k_{v}^{\text {cont }}(s)$ is the continuum absorption coefficient. Line width $w$ consists of collisional broadening width $w_{\text {col }}$, and Doppler broadening width $w_{\text {dop }} . w_{\text {col }}$ is described using air-broadening coefficient $\gamma_{\text {air }}$ as

$w_{\mathrm{col}}=\gamma_{\mathrm{air}}(T) P\left(1-x_{\mathrm{VMR}}\right)+\gamma_{\mathrm{self}}(T) P x_{\mathrm{VMR}}$,

where $P$ is the pressure, $x_{\mathrm{VMR}}$ is the VMR and $\gamma_{\text {self }}$ is the self-broadening coefficient. The self-broadening effects for $\mathrm{ClO}$ are much smaller than the air-broadening effects since $x_{\mathrm{VMR}}$ is much smaller than 1 (the VMR of $\mathrm{ClO}$ is of order $10^{-9}$ ). Equation (2) therefore reduces to $\gamma_{\text {air }}(T) P \cdot \gamma_{\text {air }}$ depends on the temperature $T$ with a factor $n_{\text {air }}$ written as

$\gamma_{\text {air }}(T)=\gamma_{\text {air }}\left(T_{0}\right)\left(\frac{T}{T_{0}}\right)^{-n_{\text {air }}} \quad\left(T_{0}=296 \mathrm{~K}\right)$.
Line-by-line calculations were performed using a dedicated spectroscopic database for SMILES observations. The lines included in the SMILES spectroscopic database were selected according to the line selection algorithm (Sato, 2010; Baron et al., 2011) from the lines listed in the JPL spectroscopic catalog (Pickett et al., 1998) and the HITRAN 2008 catalog (Rothman et al., 2009). There were about 1200 lines in the SMILES spectroscopic database. The line intensities and the transition frequencies were adopted from the JPL catalog with some replacements with recent laboratory measurements (Cazzoli and Puzzarini, 2004, H. Ozeki, personal communication, 2010; W. G. Read, personal communication, 2011). The air-broadening coefficients, $\gamma_{\text {air }}$ and $n_{\text {air }}$, were taken from the HITRAN 2008 catalog and the laboratory measurements (Drouin and Gamache, 2008; Hoshina et al., 2008; Sato et al., 2010; Drouin, 2007; Markov and Krupnov, 1995; Mizoguchi et al., 2012; Perrin et al., 2005, e.g. W. G. Read, personal communication, 2011). The ClO spectroscopic parameters relevant to the SMILES observations are given in Table 1 . The Van Vleck and Weisskopf profile (van Vleck and Weisskopf, 1945) was used as the line shape function at the lower altitudes where the Doppler broadening width was less than 1/40th of the collisional broadening width, and the Voigt profile (Schreier and Kohlert, 2008) was used at the higher altitudes. Continuum absorption coefficients of humid and dry air were based on atmospheric opacity measurements made by Pardo et al. (2001). The dry-air continuum model was multiplied by 1.2 to be more consistent with theoretical estimates (e.g. Boissoles et al., 2003).

We estimated errors in the ClO VMR retrievals due to uncertainties in the line intensity, $\gamma_{\text {air }}$ and $n_{\text {air }}$ of the $\mathrm{ClO}$ lines. The typical uncertainties given in Table 1 were used in this error analysis, i.e. 1, 3 and $10 \%$ for the line intensity (Pickett et al., 1998), $\gamma_{\text {air }}$ and $n_{\text {air }}$ (Oh and Cohen, 1994, W. G. Read, personal communication, 2011), respectively. As a representative of effects of other molecular transitions, the effect of $\gamma_{\text {air }}$ of the strong $\mathrm{O}_{3}$ line at $650.732 \mathrm{GHz}$ was evaluated. The wing of this $\mathrm{O}_{3}$ line contributes largely to baseline of the Band $\mathrm{C}$ spectrum. We adopted the $\gamma_{\text {air }}$ of the $\mathrm{O}_{3}$ line of $3.01 \mathrm{MHz}$ Torr $^{-1}$ measured by Drouin and Gamache (2008). The error in the ClO VMR due to $3 \%$ uncertainty in the $\gamma_{\text {air }}$ of the $\mathrm{O}_{3}$ line was estimated. We also estimated the error for the $\mathrm{ClO}$ retrieval due to $20 \%$ uncertainty in the dry-air continuum model.

Temperature and pressure for the radiative transfer calculation were taken from the Goddard Earth Observing System Model, Version 5.2 (GEOS-5) (Rienecker et al., 2008) and the Mass Spectrometer and Incoherent Scatter (MSIS) climatology (Hedin, 1991) for the altitude region from the surface to $70 \mathrm{~km}$ for the former and that from 70 to $110 \mathrm{~km}$ for the latter. Uncertainties in the temperature profile have been conservatively estimated according to the comparison of the temperatures measured from Aura/MLS and GEOS-5 (Schwartz et al., 2008), i.e. $3,10,30$ and $50 \mathrm{~K}$ for the troposphere 
Table 1. Spectroscopic parameters of the ClO lines observed by SMILES. The numbers in parentheses represent uncertainties. Intensity is represented by a base-10 logarithm. The quantum numbers are represented by $J, \Omega, \Sigma, \Lambda$ and $F$ for the total angular momentum, projection of $J$ on the molecular axis (z-axis), projection of the total electron spin momentum on the z-axis, projection of the total orbit momentum on the $\mathrm{z}$-axis and the real total angular momentum including the nuclear spin momentum $I=3 / 2(\Omega=\Sigma+\Lambda, F=J+I)$.

\begin{tabular}{|c|c|c|c|c|c|c|c|c|c|c|c|c|c|}
\hline \multirow{2}{*}{$\begin{array}{c}\text { Frequency } \\
\text { (GHz) }\end{array}$} & \multirow{2}{*}{$\begin{array}{l}\text { Intensity }^{\mathrm{a}} \\
\left(\mathrm{MHz} \mathrm{nm}^{2}\right)\end{array}$} & \multirow{2}{*}{$\begin{array}{c}\gamma_{\mathrm{air}}^{\mathrm{b}} \\
\left(\mathrm{MHz} \text { Torr }^{-1}\right)\end{array}$} & \multirow{2}{*}{$\begin{array}{l}n_{\text {air }}^{\mathrm{b}} \\
(-)\end{array}$} & \multicolumn{5}{|c|}{ Quantum numbers (upper state) $^{\mathrm{a}}$} & \multicolumn{5}{|c|}{ Quantum numbers (lower state) $^{\mathrm{a}}$} \\
\hline & & & & $J^{\prime}$ & $\Omega^{\prime}$ & $\Sigma^{\prime}$ & $\Lambda^{\prime}$ & $F^{\prime}$ & $J^{\prime \prime}$ & $\Omega^{\prime \prime}$ & $\Sigma^{\prime \prime}$ & $\Lambda^{\prime \prime}$ & $F^{\prime \prime}$ \\
\hline 649.44504 & $-1.9671(<1 \%)$ & $2.86(3 \%)$ & $0.77(10 \%)$ & $35 / 2$ & $3 / 2$ & $1 / 2$ & -1 & 19 & $33 / 2$ & $3 / 2$ & $1 / 2$ & +1 & 18 \\
\hline 649.44504 & $-1.9920(<1 \%)$ & $2.86(3 \%)$ & $0.77(10 \%)$ & $35 / 2$ & $3 / 2$ & $1 / 2$ & -1 & 18 & $33 / 2$ & $3 / 2$ & $1 / 2$ & +1 & 17 \\
\hline 649.44504 & $-2.0170(<1 \%)$ & $2.86(3 \%)$ & $0.77(10 \%)$ & $35 / 2$ & $3 / 2$ & $1 / 2$ & -1 & 17 & $33 / 2$ & $3 / 2$ & $1 / 2$ & +1 & 16 \\
\hline 649.44504 & $-2.0420(<1 \%)$ & $2.86(3 \%)$ & $0.77(10 \%)$ & $35 / 2$ & $3 / 2$ & $1 / 2$ & -1 & 16 & $33 / 2$ & $3 / 2$ & $1 / 2$ & +1 & 15 \\
\hline 649.45117 & $-1.9671(<1 \%)$ & $2.86(3 \%)$ & $0.77(10 \%)$ & $35 / 2$ & $3 / 2$ & $1 / 2$ & +1 & 19 & $33 / 2$ & $3 / 2$ & $1 / 2$ & -1 & 18 \\
\hline 649.45117 & $-1.9920(<1 \%)$ & $2.86(3 \%)$ & $0.77(10 \%)$ & $35 / 2$ & $3 / 2$ & $1 / 2$ & +1 & 18 & $33 / 2$ & $3 / 2$ & $1 / 2$ & -1 & 17 \\
\hline 649.45117 & $-2.0170(<1 \%)$ & $2.86(3 \%)$ & $0.77(10 \%)$ & $35 / 2$ & $3 / 2$ & $1 / 2$ & +1 & 17 & $33 / 2$ & $3 / 2$ & $1 / 2$ & -1 & 16 \\
\hline 649.45117 & $-2.0420(<1 \%)$ & $2.86(3 \%)$ & $0.77(10 \%)$ & $35 / 2$ & $3 / 2$ & $1 / 2$ & +1 & 16 & $33 / 2$ & $3 / 2$ & $1 / 2$ & -1 & 15 \\
\hline
\end{tabular}

${ }^{\text {a }}$ The JPL catalog version 3 (Pickett et al., 1998). ${ }^{\text {b }}$ W. G. Read, personal communication, 2011.

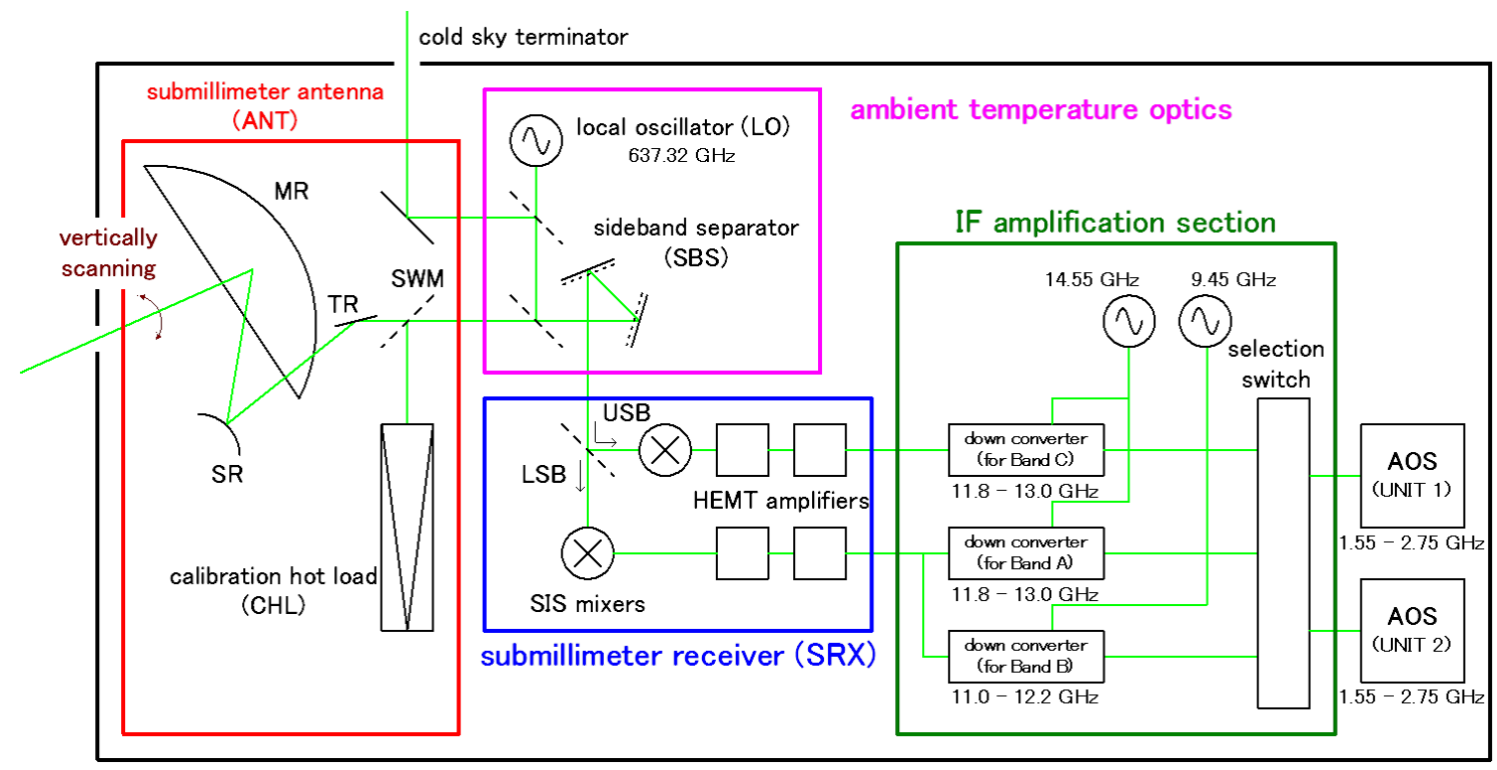

Fig. 2. Schematic of the SMILES payload.

(below $11 \mathrm{~km}$ ), the stratosphere $(11-59 \mathrm{~km})$, the mesosphere $(59-96 \mathrm{~km})$ and the thermosphere (above $96 \mathrm{~km}$ ). The uncertainties in the pressure profile were conservatively set as a constant percentage of $10 \%$ for all altitudes.

\subsubsection{Instrument functions}

\section{Uncertainty in instrumental parts of forward model}

Here, we describe key instrument functions of SMILES such as the antenna beam pattern, the separation ratio of the sideband separator (SBS) and the filter response function of each channel in the spectrometer. Figure 2 shows the signal flow in the SMILES system. Further details on the SMILES instruments are described by Kikuchi et al. (2010); Masuko et al. (2002) and Ochiai et al. (2012c).

As the optical path of SMILES is well designed to minimize standing waves (the spectral ripple is as small as $0.09 \%$ of input brightness temperature, Ochiai et al., 2012c), their effects were negligible in this error analysis.

The aperture size of the offset Cassegrain antenna (ANT) is $400 \mathrm{~mm} \times 200 \mathrm{~mm}$ (Manabe et al., 2012). Its vertical beam size is $0.09^{\circ}$, in terms of the full width at half maximum (FWHM), and the field-of-view is around $3.2-4.0 \mathrm{~km}$ at the tangent heights ranging from 10 to $60 \mathrm{~km}$ in the condition of the ISS height ranging from 333 to $370 \mathrm{~km}$. Radiance $I_{v}^{\text {ANT }}$ at frequency $v$ received by a boresight solid angle of ANT is given by 
$I_{\nu}^{\mathrm{ANT}}=\int_{\Omega_{0}} I_{\nu}(\Omega) R_{\nu}^{\mathrm{ANT}}(\Omega) \mathrm{d} \Omega$,

where $I_{v}(\Omega)$ is the radiance for the direction $\Omega, R_{v}^{\mathrm{ANT}}$ is the normalized antenna beam pattern and $\Omega_{0}$ is the boresight solid angle, defined in the Level-1 processing as the angular range within $\pm 4.2^{\circ}$ from the boresight direction. The Level1 brightness temperature does not include the radiance coming from outside $\Omega_{0}$, which is estimated and subtracted from the total radiance in the Level-1 processing; more details on related uncertainties are provided below. SMILES periodically scanned atmosphere with a stepping rate of $12 \mathrm{~Hz}$ and an angular step of $0.009375^{\circ}(0.3-0.4 \mathrm{~km})$. The atmospheric limb emissions during six steps in $0.5 \mathrm{~s}$ were accumulated to generate a spectrum at one tangent height. The forward model in the L2r v2.1.5 synthesized the spectrum at one tangent height using $R_{v}^{\mathrm{ANT}}$ without adjustments for the antenna movements over six scan steps. The errors in $\mathrm{ClO}$ retrieval due to the omission of the adjustments and uncertainty in the beam size were calculated. The beam-size uncertainty used in this error analysis was $2 \%$, which was conservatively estimated from measurement errors in the pre-launch test of the antenna beam pattern.

Tangent height was geometrically measured from the antenna elevation angle and the ISS attitude. Bias in the measured tangent height was retrieved in the L2r retrieval analysis. Random uncertainty was due to measurement errors of the ISS attitude, and was estimated to be about $0.001^{\circ}$ (Ochiai et al., 2012b). It corresponds to $40 \mathrm{~m}$ in the tangent height and $0.5 \%$ in the spectrum brightness temperature, which is much smaller than the total random error discussed later. Therefore the error due to the uncertainty in the tangent height was not taken into account in this paper.

Upper sideband (USB) and lower sideband (LSB) were separated using SBS and fed to the SIS mixers for USB and LSB, respectively. The SBS configuration is described by Manabe et al. (2003). The radiance input to the USB mixer $\left(I_{\nu_{\mathrm{IF}}}^{\mathrm{UMIX}}\right)$ is expressed using the radiances in the USB $\left(I_{\nu_{\mathrm{USB}}}^{\mathrm{ANT}}\right)$ and the LSB $\left(I_{\nu_{\mathrm{LSB}}}^{\mathrm{ANT}}\right)$ received by ANT as

$I_{\nu_{\mathrm{IF}}}^{\mathrm{UMIX}}=\beta_{\nu_{\mathrm{IF}}}^{\mathrm{USB}} I_{\nu_{\mathrm{USB}}}^{\mathrm{ANT}}+\left(1-\beta_{\nu_{\mathrm{IF}}}^{\mathrm{USB}}\right) I_{\nu_{\mathrm{LSB}}}^{\mathrm{ANT}}$,

$v_{\mathrm{IF}}=v_{\mathrm{USB}}-v_{\mathrm{LO}}=v_{\mathrm{LO}}-v_{\mathrm{LSB}}$,

where $\beta_{\nu_{\mathrm{IF}}}^{\mathrm{USB}}$ is the ratio of the contribution of $I_{\nu_{\mathrm{USB}}}^{\mathrm{ANT}}$ and $\nu_{\mathrm{LO}}$ is the frequency of the local oscillator at $637.32 \mathrm{GHz}$. Ochiai et al. (2008) describe details on $\beta_{\nu_{\mathrm{IF}}}^{\mathrm{USB}} \cdot \beta_{\nu_{\mathrm{IF}}}^{\mathrm{USB}}$ ranges between 0.98 and 0.99 , but it is assumed to be one to reduce a calculation time in the retrieval processing of L2r v2.1.5. We calculated the errors in $\mathrm{ClO}$ retrieval due to this assumption and the uncertainty in the $\beta_{\nu_{\mathrm{IF}}}^{\mathrm{USB}}$ of $\pm 3 \mathrm{~dB}$.

Two acousto-optical spectrometers (AOSs), called UNIT 1 and UNIT 2, were used for spectral detection. Response functions of the AOSs were measured in orbit (Mizobuchi et al., 2012). UNIT 1 of the AOS was used for ClO observations. The $\mathrm{ClO}$ transitions at 649.445 and $649.451 \mathrm{GHz}$ are typically located around AOS channel number 535; the related FWHM of the response function is about $1.06 \mathrm{MHz}$. The uncertainty in FWHM was conservatively estimated to be $10 \%$.

\section{Uncertainty in calibration}

The Level-1b (L1b) version 007 data were used for processing L2r v2.1.5. Here, we provide a brief overview of the calibration procedure in L1b version 007. After this, we represent radiance $I$ with brightness temperature $\mathcal{T}$.

The brightness temperature averaged over $\Omega_{0}$ with a weight of $R^{\mathrm{ANT}}$ is denoted as $\mathcal{T}_{\mathrm{ANT}}$. Total brightness temperature $\mathcal{T}_{\text {MR }}$ received by ANT at the point of the main reflector (MR) is expressed as

$$
\begin{aligned}
\mathcal{T}_{\text {MR }} & =\eta_{\text {main }} \mathcal{T}_{\text {ANT }}+\eta_{\text {space }} \mathcal{T}_{\mathrm{B}}\left(T_{\text {space }}\right) \\
& +\eta_{\text {earth }} \mathcal{T}_{\mathrm{B}}\left(T_{\text {earth }}\right)+\eta_{\text {body }} \mathcal{T}_{\mathrm{B}}\left(T_{\text {body }}\right),
\end{aligned}
$$

where $\eta_{\text {main }}$ is the main beam efficiency in the solid angle region defined by $\Omega_{0} . \eta_{\text {space}}, \eta_{\text {earth }}$ and $\eta_{\text {body }}$ correspond to fractions of the antenna beam pattern integrated over the solid angles which are directed toward space, the Earth and the SMILES structural body, respectively. $T_{\text {space }}$, $T_{\text {earth }}$ and $T_{\text {body }}$ are the temperatures of space, the Earth and the SMILES structural body, respectively. $\mathcal{T}_{\mathrm{B}}(T)$ represents the brightness temperature of a black body at the temperature $T$. The main beam efficiency $\eta_{\text {main }}$ is 0.975 in the $\mathrm{L} 1 \mathrm{~b}$ version 007 . We conservatively estimated the uncertainty in $\eta_{\text {main }}$ as $2 \%$.

The fractional contributions of space, the Earth and the SMILES structural body $\left(\eta_{\text {space }}, \eta_{\text {earth }}\right.$ and $\eta_{\text {body }}$, respectively) were geometrically calculated as

$$
\begin{aligned}
& \eta_{\text {space }}=0.084\left(1-\eta_{\text {main }}\right), \\
& \eta_{\text {earth }}=0.060\left(1-\eta_{\text {main }}\right), \\
& \eta_{\text {body }}=0.856\left(1-\eta_{\text {main }}\right),
\end{aligned}
$$

for the Earth's limb observations, and

$$
\begin{aligned}
& \eta_{\text {space }}=0.140\left(1-\eta_{\text {main }}\right), \\
& \eta_{\text {earth }}=0.004\left(1-\eta_{\text {main }}\right), \\
& \eta_{\text {body }}=0.856\left(1-\eta_{\text {main }}\right),
\end{aligned}
$$

for the cold-reference measurements (cosmic microwave background). We assumed in the L1b version 007 processing that $\mathcal{T}_{\mathrm{B}}\left(T_{\text {space }}\right)$ was substantially $0 \mathrm{~K}, T_{\text {earth }}$ was $255 \mathrm{~K}$, and $T_{\text {body }}$ was the measured physical temperature of the antenna structure. $T_{\text {earth }}$ had the largest variations for $T_{\text {space }}, T_{\text {earth }}$ and $T_{\text {body }}$. We investigated errors due to uncertainties in the $T_{\text {earth }}$ of $20 \mathrm{~K}$ (typical variations in the Earth's actual atmosphere).

Joule mirror losses were taken into account in this error analysis. Brightness temperatures due to losses of the main reflector (MR), the sub-reflector (SR) and the tertiary reflector (TR) were not calibrated, although a reference brightness 
temperature from the calibration hot load (CHL) was measured every $53 \mathrm{~s}$ by inserting the switching mirror (SWM) in the beam at switching point between the TR and the fourth reflector. Brightness temperature $\mathcal{T}_{\mathrm{TR}}^{\mathrm{atm}}$ of the beam at the switching point for the atmospheric measurements is expressed as

$\mathcal{T}_{\mathrm{TR}}^{\mathrm{atm}}=\mu_{\mathrm{MR}} \mu_{\mathrm{SR}} \mu_{\mathrm{TR}} \mathcal{T}_{\mathrm{MR}}+\left(1-\mu_{\mathrm{MR}} \mu_{\mathrm{SR}} \mu_{\mathrm{TR}}\right) \mathcal{T}_{\mathrm{B}}\left(T_{\text {mirror }}\right)$,

where $\mu_{\mathrm{MR}}, \mu_{\mathrm{SR}}$ and $\mu_{\mathrm{TR}}$ are the transmission coefficients of MR, SR and TR, respectively, and $T_{\text {mirror }}$ is the temperature of the reflectors. These three reflectors were assumed to be at the same temperature $T_{\text {mirror }}$, because the mirrors were made from highly thermally conducting material (aluminum alloy) (Manabe et al., 2012). Scattering and spillover losses at these reflectors were counted in the efficiency $\eta_{\text {body }}$ and not in $\mu_{\mathrm{MR}}, \mu_{\mathrm{SR}}$ or $\mu_{\mathrm{TM}}$. Brightness temperature $\mathcal{T}_{\mathrm{TR}}^{\text {hot }}$ of the beam for the hot-reference brightness temperature at TR is

$$
\begin{aligned}
\mathcal{T}_{\mathrm{TR}}^{\text {hot }} & =\mu_{\mathrm{SWM}}\left\{\mu_{\mathrm{CHL}} \mathcal{T}_{\mathrm{B}}\left(T_{\mathrm{CHL}}\right)+\left(1-\mu_{\mathrm{CHL}}\right) \mathcal{T}_{\mathrm{RX}}\right\} \\
& +\left(1-\mu_{\mathrm{SWM}}\right) \mathcal{T}_{\mathrm{B}}\left(T_{\text {mirror }}\right),
\end{aligned}
$$

where $\mu_{\mathrm{SWM}}$ is the transmission coefficient of SWM, $\mu_{\mathrm{CHL}}$ is one minus the reflection coefficient of $\mathrm{CHL}, T_{\mathrm{CHL}}$ is the temperature of $\mathrm{CHL}$ and $\mathcal{T}_{\mathrm{RX}}$ is brightness temperature of incident to CHL. The coefficients $\mu_{\mathrm{MR}}, \mu_{\mathrm{SR}}, \mu_{\mathrm{TR}}$ and $\mu_{\mathrm{SWM}}$ are $0.9955,0.9958,0.9956$ and 0.9959 , respectively. These values were estimated from laboratory reflection measurements of materials that have identical surfaces as reflectors. Uncertainties in these coefficients were estimated to be $0.1 \%$. A power reflection coefficient of CHL was negligibly small (less than $-60 \mathrm{~dB}$ ), and $\mu_{\mathrm{CHL}}$ was assumed to be one.

The receiver output, i.e. the quantized output from AOS, deviates from a linear relation to the input brightness temperature because of gain nonlinearity of the receiver and the spectrometer components. Output $V_{v}$ from AOS at the channel corresponding to the frequency $v$ is given by

$$
V_{v}=G_{v}\left(1-\alpha \bar{V}-\alpha^{\prime} V_{v}\right) p_{v}+V_{0},
$$

where $G_{v}$ is the total system gain, $\bar{V}$ is the average of $V_{v}$ over all spectrometer channels, $V_{0}$ is the offset of the AOS output, and $p_{v}$ is the total input power to the receiver. $\bar{V}$ was assumed to be 12000 and 22500 for the cold and hot references, respectively, in this error analysis. The input power $p_{v}$ is proportional to a sum of $\mathcal{T}_{\mathrm{ANT}}$ and system noise temperature $\mathcal{T}_{\text {sys }} ; \mathcal{T}_{\text {sys }}$ includes system noise, the brightness coming from direction $\Omega_{0}$ and the emissions from the lossy reflectors. Coefficients $\alpha$ and $\alpha^{\prime}$ represent receiver gain nonlinearity (Ochiai et al., 2012a). $\alpha$ was $1.884 \times 10^{-6}$ and was measured in the pre-launch test. We call $\alpha$ a "gain-compression parameter". We conservatively estimated uncertainty in $\alpha$ as $20 \%$ including errors from the signals outside the spectrometer passbands. The term $\alpha^{\prime} V_{v}$ did not have large effects on the $\mathrm{ClO}$ retrieval compared with the term $\alpha \bar{V}$ and was ignored in this error analysis.
The Level-1 processing produces brightness temperature spectrum $\boldsymbol{y}_{\mathrm{obs}}$, which is the estimation of $\mathcal{T}_{\mathrm{ANT}}$ using $V_{\nu}$ for the atmospheric limb observations, the cold (space) and hot (CHL) references. These cold and hot references were measured every 53 s (Ochiai et al., 2008).

\subsection{Inversion analysis}

We employed the optimal estimation method (Rodgers, 2000) for the L2r retrieval analysis of version 2.1.5 (Baron et al., 2011). The method leads to the maximum a posteriori solution, which minimizes the value of $\chi^{2}$ :

$$
\begin{aligned}
\chi^{2} & =\left[\boldsymbol{y}_{\text {obs }}-\mathcal{F}(\boldsymbol{x}, \boldsymbol{b})\right]^{T} \mathbf{S}_{y}^{-1}\left[\boldsymbol{y}_{\mathrm{obs}}-\mathcal{F}(\boldsymbol{x}, \boldsymbol{b})\right] \\
& +\left(\boldsymbol{x}-\boldsymbol{x}_{\mathrm{a}}\right)^{T} \mathbf{S}_{\mathrm{a}}^{-1}\left(\boldsymbol{x}-\boldsymbol{x}_{\mathrm{a}}\right),
\end{aligned}
$$

where $\mathcal{F}$ is the forward model, $\boldsymbol{x}$ is the vector of the atmospheric true state, and $\boldsymbol{b}$ is the vector of the parameters used in $\mathcal{F} . \mathbf{S}_{y}$ is the covariance matrix for spectrum noise $\epsilon_{y}, \boldsymbol{x}_{\mathrm{a}}$ is the a priori state of $\boldsymbol{x}$ and $\mathbf{S}_{\mathrm{a}}$ is the covariance matrix for the natural variability of $\boldsymbol{x}$. We use $\mathbf{S}_{y}$ and $\mathbf{S}_{\mathrm{a}}$ as tuning parameters to obtain a stable retrieval.

$\mathbf{S}_{y}[i, j]=\epsilon_{y}^{2} \delta_{i, j}, \quad \epsilon_{y}=0.5 \mathrm{~K}$,

where $\delta_{i, j}$ is the Kronecker delta.

$$
\begin{aligned}
& \mathbf{S}_{\mathrm{a}}[i, j]=\boldsymbol{\epsilon}_{\mathrm{a}}[i] \boldsymbol{\epsilon}_{\mathrm{a}}[j] \exp \left[-\frac{|z[i]-z[j]|}{z_{\mathrm{c}}}\right], \\
& \boldsymbol{\epsilon}_{\mathrm{a}}[i]=\epsilon_{1} \boldsymbol{x}_{\mathrm{a}}[i]+\epsilon_{2}, \quad\left(\epsilon_{1}, \epsilon_{2}\right)=\left(0.5,2.0 \times 10^{-10}\right)
\end{aligned}
$$

where $z_{\mathrm{c}}$ is the correlation length that constrains the vertical continuity in the retrieved profile, and is set to be $6 \mathrm{~km}$.

A vertical VMR profile of $\mathrm{ClO}$ was retrieved using each scan of the Band $\mathrm{C}$ spectrum with a reduced frequency window of $649.4 \pm 0.2 \mathrm{GHz}$. The $\mathrm{ClO}$ a priori profile was the same as that for Odin/SMR, which was based on the UARS/MLS climatology. The weighting functions (see Eq. 22) were calculated at altitudes from 16 to $43 \mathrm{~km}$ with $3-\mathrm{km}$ intervals, from 43 to $55 \mathrm{~km}$ with $4-\mathrm{km}$ intervals and from 55 to $95 \mathrm{~km}$ with $5-\mathrm{km}$ intervals. We used the measurement spectra whose tangent heights range from 15 to $90 \mathrm{~km}$. The accompanying retrieval parameters were a second-order polynomial baseline, an offset of the AOS frequency and a line-of-sight elevation angle for each scan. Although the offset of the line-of-sight elevation angle was also retrieved using the $\mathrm{O}_{3}$ line in Bands $\mathrm{A}$ and $\mathrm{B}$ (Baron et al., 2011), the offset used for the $\mathrm{ClO}$ retrieval was independently retrieved using the $\mathrm{ClO}$ lines and the baseline spectra in Band $\mathrm{C}$. The pointing information came from the pressure broadening of the line in combination with the assumed a priori knowledge in the background atmosphere. The temperature and pressure profiles were not retrieved in the Band $\mathrm{C}$ retrieval. The VMR of $\mathrm{H}_{2} \mathrm{O}$ was also set as a variable with an intention of improving the fit of the baseline. 


\subsection{Method of error calculation}

Total error $\boldsymbol{E}_{\text {total }}$ is given by

$\boldsymbol{E}_{\text {total }}[i]=\sqrt{\boldsymbol{E}_{\text {noise }}^{2}[i]+\boldsymbol{E}_{\text {smooth }}^{2}[i]+\boldsymbol{E}_{\text {param }}^{2}[i]+\boldsymbol{E}_{\text {calib }}^{2}[i]}$,

where $\boldsymbol{E}_{\text {noise }}$ is the error due to spectrum noise, $\boldsymbol{E}_{\text {smooth }}$ is the smoothing error, $\boldsymbol{E}_{\text {param }}$ is the error due to uncertainties in the model parameters and $\boldsymbol{E}_{\text {calib }}$ is the error due to inaccuracies in the spectrum calibration. We conservatively estimated the uncertainties for each error source described in Sects. 2.1 and 2.2. We took the root-sum-square values for the estimation of the total systematic error, since we considered as many (16) error sources as possible and most of the error sources were conservatively estimated.

We assumed that the true state was identical to the a priori state $\boldsymbol{x}_{\mathrm{a}}$, and synthesized reference spectrum $\boldsymbol{y}_{\text {ref }}$ using $\boldsymbol{x}_{\mathrm{a}}$. Inversion calculation was performed using $\boldsymbol{y}_{\text {ref }}$. We used retrieved state $\boldsymbol{x}_{\text {ref }}$ (not $\boldsymbol{x}_{\mathrm{a}}$ ) as a reference profile for this error analysis as this removed the characteristics included in the retrieval algorithm itself.

$\boldsymbol{x}_{\text {ref }}=\mathcal{I}\left(\boldsymbol{y}_{\text {ref }}, \boldsymbol{b}_{0}\right)$,

where $\mathcal{I}$ is the inversion function and $\boldsymbol{b}_{0}$ is the vector of model parameters. The reference profile is shown in Fig. 3 with the difference in $\boldsymbol{x}_{\mathrm{a}}$ and $\boldsymbol{x}_{\text {ref }}$. This figure also shows measurement response $\boldsymbol{m}$ and averaging kernel A. Details on $\boldsymbol{m}$ are explained by Baron et al. (2002), and we simplified them as

$$
\begin{aligned}
& \boldsymbol{m}[i]=\sum_{j}|\mathbf{A}[i, j]|, \\
& \mathbf{A}=\frac{\partial \hat{\boldsymbol{x}}}{\partial \boldsymbol{x}}=\mathbf{D} \mathbf{K}, \\
& \mathbf{D}=\frac{\partial \hat{\boldsymbol{x}}}{\partial \boldsymbol{y}}=\left(\mathbf{K}^{T} \mathbf{S}_{y}^{-1} \mathbf{K}+\mathbf{S}_{\mathrm{a}}^{-1}\right)^{-1} \mathbf{K}^{T} \mathbf{S}_{y}^{-1}, \\
& \mathbf{K}=\frac{\partial \boldsymbol{y}}{\partial \boldsymbol{x}},
\end{aligned}
$$

where $\hat{\boldsymbol{x}}$ was a solution of the retrieval. Weighting function $\mathbf{K}$ was analytically calculated. $\boldsymbol{m}, \mathbf{A}$ and contribution function D were consecutively given using $\mathbf{K}$ (Urban et al., 2004). Typical vertical resolutions of L2r version 2.1.5 were about $3-5$ and $5-8 \mathrm{~km}$ for altitude regions of $30-50$ and $50-70 \mathrm{~km}$, respectively.

\subsubsection{Retrieval error}

Retrieval error consists of the error due to spectrum statistical noise $\boldsymbol{E}_{\text {noise }}$ and the smoothing error $\boldsymbol{E}_{\text {smooth }}$.

$\mathbf{S}_{\text {noise }}=\mathbf{D S}_{y} \mathbf{D}^{T}$,

$\boldsymbol{E}_{\text {noise }}[i]=\sqrt{\mathbf{S}_{\text {noise }}[i, i]}$,

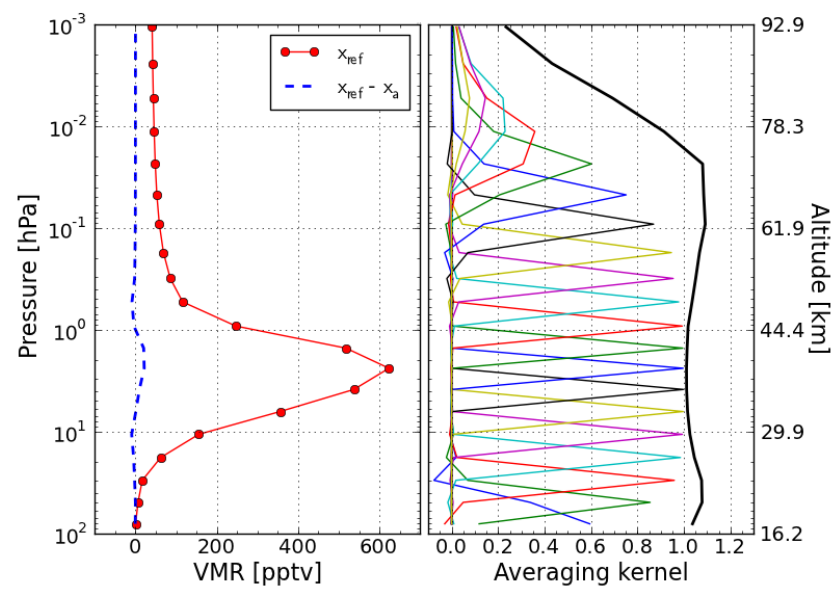

Fig. 3. Reference profile $\boldsymbol{x}_{\text {ref }}$ of ClO VMR used in the error analysis. The left figure shows $\boldsymbol{x}_{\text {ref }}$ and the difference in $\boldsymbol{x}_{\mathrm{a}}$ and $\boldsymbol{x}_{\text {ref }}$. The right figure shows the measurement response (black solid line) and the averaging kernels.

where $\mathbf{S}_{\text {noise }}$ is the error covariance matrix for measurement noise.

$\mathbf{S}_{\text {smooth }}=(\mathbf{A}-\mathbf{U}) \mathbf{S}_{\mathrm{a}}(\mathbf{A}-\mathbf{U})^{T}$,

$\boldsymbol{E}_{\text {smooth }}[i]=\sqrt{\mathbf{S}_{\text {smooth }}[i, i]}$,

where $\mathbf{S}_{\text {smooth }}$ is the error covariance matrix for errors derived from $\mathbf{S}_{\mathrm{a}}$ and $\mathbf{U}$ is the unit matrix. Note that $\boldsymbol{E}_{\text {smooth }}$ has both aspects for being included in random error $\left(\boldsymbol{E}_{\text {random }}\right)$ and systematic error $\left(\boldsymbol{E}_{\text {systematic }}\right)$. The random aspect in $\boldsymbol{E}_{\text {smooth }}$ results from applying a finite vertical retrieval grid to true state $\boldsymbol{x}$. The systematic aspect arises by making $\hat{\boldsymbol{x}}$ to be identical to $\boldsymbol{x}_{\mathrm{a}}$ where the measurement response $\boldsymbol{m}$ is low. We focused on the data of L2r version 2.1.5 that satisfy $\boldsymbol{m}>0.8$ in this paper, where $\boldsymbol{E}_{\text {smooth }}$ was more random than systematic. We categorized $\boldsymbol{E}_{\text {smooth }}$ as $\boldsymbol{E}_{\text {random }}$ in the following study.

\subsubsection{Uncertainty in model parameters}

Errors due to the uncertainties in the spectroscopic parameters, the instrument functions and the atmospheric profiles of temperature and pressure are categorized into $\boldsymbol{E}_{\text {param }} \cdot \boldsymbol{E}_{\text {param }}$ is calculated as

$\boldsymbol{E}_{\text {param }}=\mathcal{I}\left(\boldsymbol{y}_{\text {ref }}, \boldsymbol{b}_{0}+\boldsymbol{\Delta} \boldsymbol{b}\right)-\mathcal{I}\left(\boldsymbol{y}_{\mathrm{ref}}, \boldsymbol{b}_{0}\right)$,

where $\boldsymbol{y}_{\text {ref }}$ is the reference spectrum and $\boldsymbol{b}_{0}$ is a vector of model parameters.

We took into account vertical correlations for the error calculations of the uncertainties in the atmospheric temperature and pressure profiles. We calculated the $\mathrm{ClO}$ errors due to the temperature and pressure profiles employing singular value decomposition as follows. The model parameter $\boldsymbol{b}_{0}$ has correlated uncertainty $\boldsymbol{\Delta} \boldsymbol{b} . \boldsymbol{b}_{0}$ is represented with respect to the 
Table 2. Summary of the error sources for a single-scan observation.

\begin{tabular}{|c|c|c|c|c|}
\hline $\begin{array}{l}\text { Systematic (S) } \\
\text { or Random (R) }\end{array}$ & $\begin{array}{l}\text { Error } \\
\text { source }\end{array}$ & $\begin{array}{l}\text { Uncertainty in } \\
\text { error source }\end{array}$ & $\begin{array}{l}\text { Error at } \\
2.5 \mathrm{hPa}(\mathrm{pptv})\end{array}$ & $\begin{array}{l}\text { Calculation } \\
\text { method }\end{array}$ \\
\hline $\mathrm{R}$ & Spectrum noise & $\epsilon_{y}^{1}$ & 14 & Eq. (23) \\
\hline $\mathrm{R}$ & Smoothing error & $\epsilon_{\mathrm{a}}^{2}$ & 2.9 & Eq. (24) \\
\hline $\mathrm{R}$ & Temperature profile & footnote ${ }^{3}$ & 9.2 & Eq.(25) \\
\hline $\mathrm{R}$ & Pressure profile & $10 \%$ & 20 & Eq. (25) \\
\hline S & Line intensity ${ }^{4}$ & $1 \%$ & 6.3 & Eq. (25) \\
\hline S & $\gamma_{\text {air }}\left(\right.$ Air-broadening coefficient) ${ }^{4}$ & $3 \%$ & 17 & Eq. (25) \\
\hline$S$ & $n_{\text {air }}$ (Temperature dependence of $\left.\gamma_{\text {air }}\right)^{4}$ & $10 \%$ & 15 & Eq. (25) \\
\hline$S$ & $\gamma_{\text {air }}$ of the $\mathrm{O}_{3}$ line at $650.732 \mathrm{GHz}$ & $3 \%$ & 0.022 & Eq. (25) \\
\hline S & Dry-air continuum & $20 \%$ & 3.5 & Eq. (25) \\
\hline S & Antenna beam pattern & footnote ${ }^{5}$ & 3.8 & Eq. (25) \\
\hline S & SBS characteristics & footnote ${ }^{6}$ & 0.13 & Eq. (25) \\
\hline S & AOS response function & $10 \%$ in FWHM & 0.24 & Eq. (25) \\
\hline S & Gain-compression parameter $\alpha$ & $20 \%$ & 6.2 & Eq. (31) \\
\hline S & Main beam efficiency $\eta_{\text {main }}$ & $2 \%$ & 1.9 & Eq. (31) \\
\hline S & Joule loss of mirrors $\mu$ & $0.1 \%$ & 0.042 & Eq. (31) \\
\hline $\mathrm{S}$ & Temperature of the Earth $T_{\text {earth }}$ & $20 \mathrm{~K}$ & 0.010 & Eq. (31) \\
\hline
\end{tabular}

\footnotetext{
${ }^{1}$ Given by Eq. (14). ${ }^{2}$ Given by Eq. (16). ${ }^{3} 3 \mathrm{~K}$ in the troposphere, $10 \mathrm{~K}$ in the stratosphere, $30 \mathrm{~K}$ in the mesosphere and $50 \mathrm{~K}$ in the thermosphere. ${ }^{4}$ Of the $\mathrm{ClO}$ lines at 649.445 and $649.451 \mathrm{GHz} .{ }^{5} 2 \%$ uncertainty in FWHM of $R^{\mathrm{ANT}}$ and no adjustment of six steps in one tangent height. ${ }^{6}$ Assuming $\beta^{\mathrm{USB}}=1$ and $\pm 3 \mathrm{~dB}$ in $\beta^{\mathrm{USB}}$.
}

eigenfunctions of covariance matrix $\mathbf{S}_{b}$ to obtain a representation of $\boldsymbol{b}_{0}$ with uncorrelated components, called $\overline{\boldsymbol{b}}_{0}$, using orthogonal matrix $\mathbf{B}\left(\mathbf{B ~ B}^{T}=\mathbf{U}\right)$.

$\boldsymbol{b}_{0}=\mathbf{B} \overline{\boldsymbol{b}}_{0}, \quad \overline{\boldsymbol{b}}_{0}=\mathbf{B}^{T} \boldsymbol{b}_{0}$.

A covariance matrix of $\overline{\boldsymbol{b}}_{0}\left(\mathbf{S}_{\bar{b}}\right)$ is a diagonal matrix and composed of the eigenvalues of $\mathbf{S}_{b}$. $\mathbf{S}_{\bar{b}}$ is expressed using $\mathbf{S}_{b}$ and $\mathbf{B}$ as

$\mathbf{S}_{\bar{b}}=\mathbf{B}^{T} \mathbf{S}_{b} \mathbf{B}$.

The covariance matrix of the temperature uncertainties is expressed as

$\mathbf{S}_{b}[i, j]=\boldsymbol{\epsilon}_{T}[i] \boldsymbol{\epsilon}_{T}[j] \exp \left\{-\frac{(z[i]-z[j])^{2}}{2 z_{\mathrm{c}}^{\prime 2}}\right\}$,

where $\boldsymbol{\epsilon}_{T}[i]$ is the temperature uncertainty at $i$-th altitude $z[i] . z_{\mathrm{c}}^{\prime}$ is the correlation length and is set to be $6 \mathrm{~km}$ (the same as $z_{c}$ in Eq. 15). $\mathbf{S}_{\bar{b}}$ and $\mathbf{B}$ are computed from $\mathbf{S}_{b}$ using numerical linear algebra packages. The $\mathrm{ClO}$ VMR error $\boldsymbol{\varepsilon}_{\text {param }}^{i}$ due to the uncertainty at the $i$-th altitude level is given by

$\boldsymbol{\varepsilon}_{\text {param }}^{i}=\mathcal{I}\left(\boldsymbol{y}_{\text {ref }}, \boldsymbol{b}_{0}+\sqrt{\mathbf{S}_{\bar{b}}[i, i]} \mathbf{B}^{i}\right)-\mathcal{I}\left(\boldsymbol{y}_{\text {ref }}, \boldsymbol{b}_{0}\right)$,

where $\mathbf{B}^{i}$ is the $i$-th row vector of $\mathbf{B}$. All $\varepsilon_{\text {param }}^{i}$ values are added by taking the root-sum-square.

$\mathcal{E}_{\text {param }}[i]=\sqrt{\sum_{j} \boldsymbol{\varepsilon}_{\text {param }}^{j}[i]^{2}}$.

\subsubsection{Calibration inaccuracy}

Errors due to the inaccuracies in the spectrum calibration $\boldsymbol{E}_{\text {calib }}$ are calculated as

$\boldsymbol{E}_{\text {calib }}=\mathbf{D} \boldsymbol{\Delta} \boldsymbol{y}$,

where $\boldsymbol{\Delta} \boldsymbol{y}$ is the difference between the values using the calibration parameter from $\mathrm{L} 1 \mathrm{~b}$ processing and that with the added uncertainty.

\section{Results of error analysis}

Error analysis was carried out for all possible error sources listed in Table 2. We separately discuss the results obtained from the error analysis for the random error $\boldsymbol{E}_{\text {random }}$ and the systematic error $\boldsymbol{E}_{\text {systematic }}$. $\boldsymbol{E}_{\text {random }}$ can be decreased by averaging several profiles; on the other hand, $\boldsymbol{E}_{\text {systematic }}$ remains constant. $\boldsymbol{E}_{\text {random }}$ consists of $\boldsymbol{E}_{\text {noise }}, \boldsymbol{E}_{\text {smooth }}$ and $\boldsymbol{E}_{\text {param }}$ due to the uncertainties in the temperature and pressure profiles. $\boldsymbol{E}_{\text {systematic }}$ consists of $\boldsymbol{E}_{\text {param }}$ due to the uncertainties in the spectroscopic parameters, the instrument functions and $\boldsymbol{E}_{\text {calib. Total error for averaging } N \text { profiles is given }}$ by

$\boldsymbol{E}_{\text {total }}(N)[i]=\sqrt{\boldsymbol{E}_{\text {systematic }}^{2}[i]+\frac{\boldsymbol{E}_{\text {random }}^{2}(1)[i]}{N},}$

where $\boldsymbol{E}_{\text {random }}(1)$ is the random error for a single-scan observation. 


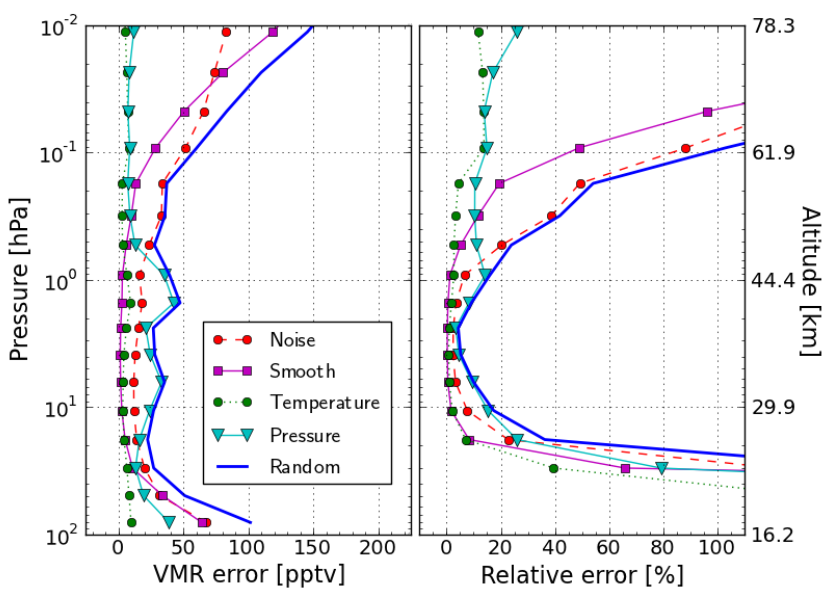

Fig. 4. Summary of the random errors for a single-scan observation. Red: $\boldsymbol{E}_{\text {noise }}$. Purple: $\boldsymbol{E}_{\text {smooth }}$ Green: error from temperature profile; the uncertainties are $3,10,30$ and $50 \mathrm{~K}$ for the troposphere (below $11 \mathrm{~km})$, the stratosphere $(11-59 \mathrm{~km})$, the mesosphere $(59$ $96 \mathrm{~km}$ ) and the thermosphere (above $96 \mathrm{~km}$ ). Cyan: error from pressure profile $(10 \%)$. Blue: total random error.

\subsection{Random error}

Figure 4 shows the error budgets for $\boldsymbol{E}_{\text {random }}$, i.e. $\boldsymbol{E}_{\text {noise, }}$, $\boldsymbol{E}_{\text {smooth }}$ and $\boldsymbol{E}_{\text {param }}$ for the temperature and pressure profiles. This paper presents both absolute VMR errors (left) and relative errors (right) for all results in the error calculations. Relative errors were calculated as absolute VMR errors divided by $\boldsymbol{x}_{\text {ref }} . \boldsymbol{E}_{\text {noise }}$ and $\boldsymbol{E}_{\text {smooth }}$ were less than $20 \%$ at pressures between 0.6 and $20 \mathrm{hPa}$ where the ClO VMR was enhanced. The errors in the $\mathrm{ClO}$ retrieval due to the uncertainties in the atmospheric temperature and pressure profiles were calculated employing singular value decomposition (Eq. 30). The errors due to the temperature profile were within $5 \%$ at pressures between 0.2 and $20 \mathrm{hPa}$ and increased at pressures larger than $10 \mathrm{hPa}$, even though there were smaller uncertainties at these lower altitudes. The errors due to the pressure profile were increased to more than $50 \%$ at pressures larger than $2 \mathrm{hPa}$ and were almost constant at $10-20 \%$ at pressures smaller than $2 \mathrm{hPa}$. The temperature and pressure profiles are related to several other parameters such as $\gamma_{\text {air }}$ and $n_{\text {air }}$, which increases the contribution of the uncertainties in the temperature and pressure profiles to the $\mathrm{ClO}$ retrieval.

The total random error was given by the root-sum-square of the retrieval errors and the errors due to the temperature and pressure profiles. At pressures smaller than $0.1 \mathrm{hPa}$, the retrieval errors were dominant and $\boldsymbol{E}_{\text {random }}$ was increased from 50 to 200 pptv (>100\%). $\boldsymbol{E}_{\text {random was about } 30-}$ $50 \mathrm{pptv}$ at pressures larger than $0.1 \mathrm{hPa}$. The pressure profile made the largest contribution to the random error in the stratosphere.

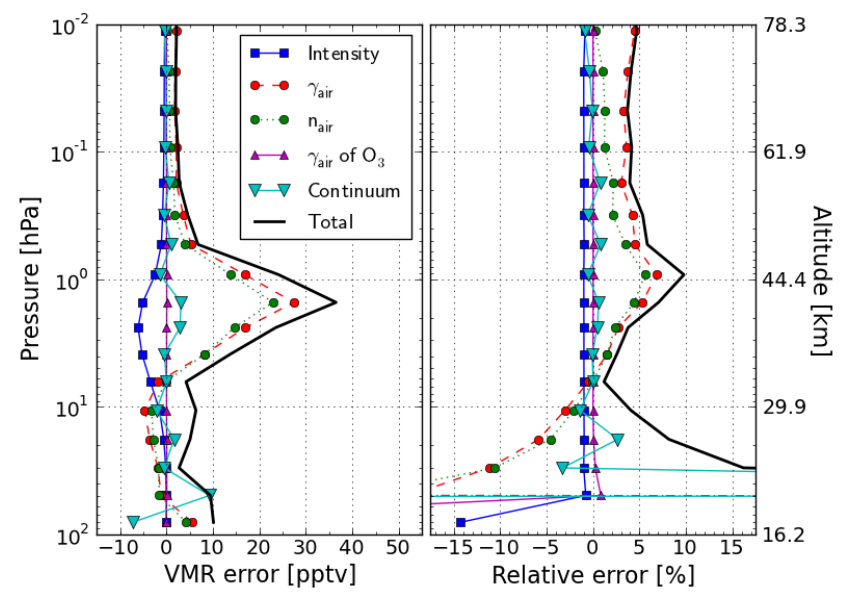

Fig. 5. Same as Fig. 4 except for the errors from the spectroscopic parameters. Blue: $+1 \%$ uncertainty in line intensity, red: $+3 \%$ uncertainty in $\gamma_{\text {air }}$, and green: $+10 \%$ uncertainty in $n_{\text {air }}$ of the $\mathrm{ClO}$ transitions at 649.445 and $649.451 \mathrm{GHz}$. Purple: $+3 \%$ uncertainty in $\gamma_{\text {air }}$ for the $\mathrm{O}_{3}$ transition at $650.732 \mathrm{GHz}$. Cyan: $+20 \%$ uncertainty in the dry-air continuum. Black: total error for the five components.

\subsection{Systematic error}

\subsubsection{Error due to uncertainty in spectroscopic parameters}

Figure 5 shows the error budgets for the spectroscopic parameters. The bold black line represents the total error calculated as the root-sum-square values for the spectroscopic parameters we investigated. The total error is around $4 \%$ at the pressures smaller than $0.05 \mathrm{hPa}$. The largest contribution comes from the uncertainty in $\gamma_{\text {air }}$ for those from the spectroscopic parameters. The error due to the $3 \%$ uncertainty in $\gamma_{\text {air }}$ is about $5 \%$ for all pressures, and the maximum is $27 \mathrm{pptv}$ $(8 \%)$ at around $1 \mathrm{hPa}$. We can see that the sign of VMR difference reverses at around $7 \mathrm{hPa}$. When $\gamma_{\text {air }}$ is larger, intensity around the center of the line of the synthesized spectrum is lower while the intensities in the wings are higher. The $\mathrm{ClO}$ VMR at larger pressures is retrieved from the wings of the $\mathrm{ClO}$ lines, whereas that at smaller pressures is derived from the center of the line. Rate of contributions from the center of the line versus those from the wings increases with altitude. Therefore, a smaller VMR is retrieved at larger pressures and larger VMR is retrieved at smaller pressures, by using a larger value of $\gamma_{\text {air }}$.

The error from $n_{\text {air }}$ follows that from $\gamma_{\text {air }}$. The vertical trends in the errors from $\gamma_{\text {air }}$ and $n_{\text {air }}$ are similar. According to the definition of Eq. (3), increasing $n_{\text {air }}$ increases $\gamma_{\text {air }}$ in the atmosphere whose temperature is lower than $296 \mathrm{~K}$. Such temperature conditions are satisfied at most altitudes observed by SMILES. The uncertainty in the line intensity almost straightforwardly propagates to the error in the $\mathrm{ClO}$ VMR at pressures smaller than $50 \mathrm{hPa}$, but with an opposite 


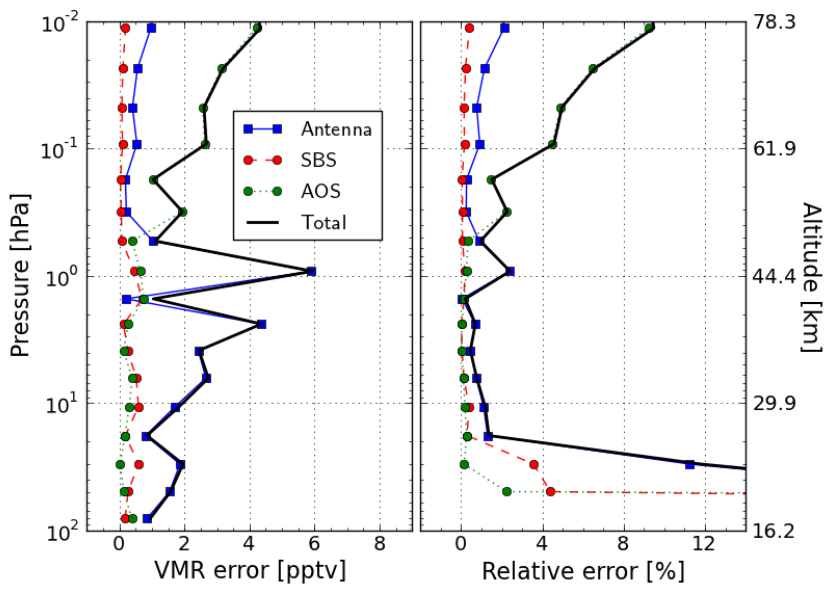

Fig. 6. Same as Fig. 4 except for errors from the instrument functions in the forward model. Blue: error from the antenna beam pattern. Red: error from the SBS. Green: $10 \%$ uncertainty in the width of the AOS response function. Black: total error of three components.

sign; i.e., $+1 \%$ uncertainty in the line intensity results in about $-1 \%$ relative error. The error from the dry-air continuum model increased to more than $10 \%$ at the pressures larger than $10 \mathrm{hPa}$. The continuum model affects the baseline correction in the retrieval particularly at larger pressures. The spectral line shape of $\mathrm{ClO}$ broadens as pressure increases, which makes it more difficult to distinguish the $\mathrm{ClO}$ signals and the baseline. The error due to the uncertainty in $\gamma_{\text {air }}$ of the ozone line at $650.732 \mathrm{GHz}$ is negligibly small.

\subsubsection{Error due to uncertainty in instrument functions}

\section{Uncertainty in instrument-related parts of forward model}

Figure 6 shows the error budgets for the instrument functions in the forward model, i.e. the antenna beam patterns and the characteristics of SBS and the AOS response functions. The bold black line represents the total error calculated as the root-sum-square value of the errors from the three instrument functions. The total error is less than $4 \%$ at the pressures between 0.1 and $10 \mathrm{hPa}$. A dominant factor is the AOS response function at the pressures smaller than $0.3 \mathrm{hPa}$. The $\mathrm{ClO}$ retrieval at smaller pressures is more sensitive to the AOS response function since the spectral line width becomes comparable to or smaller than the width of the AOS response function.

The error from the ANT is the largest of the instrument functions between 0.6 and $10 \mathrm{hPa}$. We individually calculated the errors due to the $2 \%$ uncertainty in the beam size and the lack of the adjustment of the antenna movements during the data integration time for the measurement spectrum at one tangent height. The error from the ANT plotted in Fig. 6 is the root-sum-square value of these two errors. It seems that

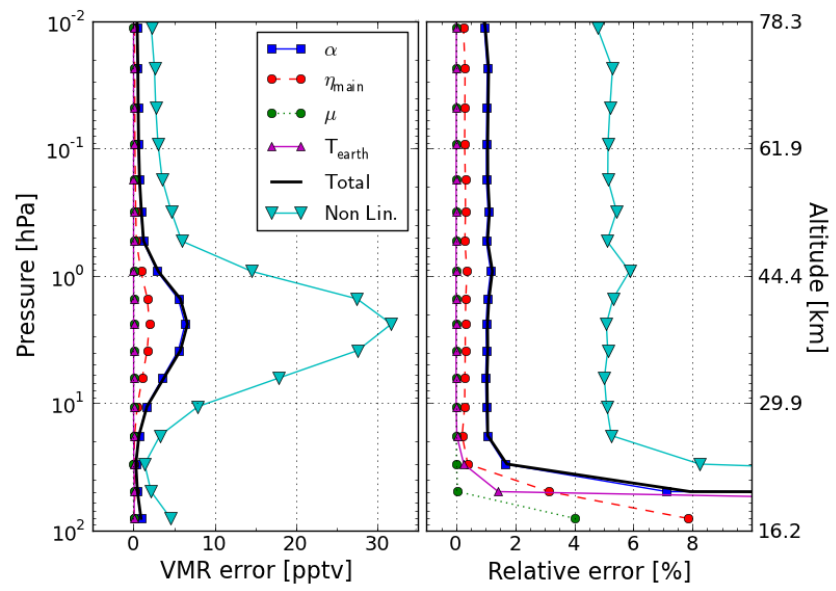

Fig. 7. Same as Fig. 4 except for the uncertainty in the calibration parameters. Blue: $20 \%$ uncertainty in the gain-compression parameter $\alpha$. Red: $2 \%$ uncertainty in the main beam efficiency $\eta_{\text {main }}$. Green: total error due to $0.1 \%$ uncertainties in the Joule losses $\mu$ for mirrors (MR, SR, TR and SWM). Purple: $20 \mathrm{~K}$ uncertainty in the temperature of the Earth $T_{\text {earth. }}$ Black: total error due to the inaccuracies of the spectrum calibration. Cyan: error due to nonlinearity being neglected between brightness temperature $\mathcal{T}$ and AOS output $V$.

the error from the ANT oscillates between 3 and $1 \mathrm{hPa}$, although the amplitude is small (about 6 pptv). The error from the SBS is the root-sum-square value of the errors due to the $\pm 3 \mathrm{~dB}$ uncertainty in $\beta^{\mathrm{USB}}$ and assuming $\beta^{\mathrm{USB}}=1$ in the $\mathrm{L} 2 \mathrm{r}$ retrieval processing. The error from the SBS has the smallest contribution of the three instruments.

\section{Uncertainty in spectrum calibration}

Figure 7 shows the error budgets due to the uncertainties in the calibration parameters, i.e. the gain-compression parameter $\alpha$, the main beam efficiency $\eta_{\text {main }}$, the Joule losses of the mirrors $\mu$ and the temperature of the Earth $T_{\text {earth }}$. The total error is given by the root-sum-square of the errors due to the uncertainties in these calibration parameters, and it is about $1 \%$ between 0.01 and $20 \mathrm{hPa}$. The error from $\alpha$ is the largest and is followed by that from $\eta_{\text {main }}$. The error from $\mu$ is given by the root-sum-square of the individually calculated errors in the $0.1 \%$ uncertainties in the Joule losses of MR, SR, TR and SWM. The errors from $\mu$ and $T_{\text {earth }}$ are negligible.

We calculated the effect by taking into account nonlinearity between the AOS output $V$ and the brightness temperature $\mathcal{T}$, which is indicated by the cyan line in Fig. 7 labeled "Non Lin.". Note that it is not included in the total error of the $\mathrm{ClO}$ retrieval in this error analysis. It makes a contribution as large as approximately $5 \%$ relative error, which is about five times that of the total error from the uncertainties in the calibration parameters. This clearly indicates that it is essential to carefully consider the nonlinearity between $V$ and $\mathcal{T}$ in the spectrum calibration. 


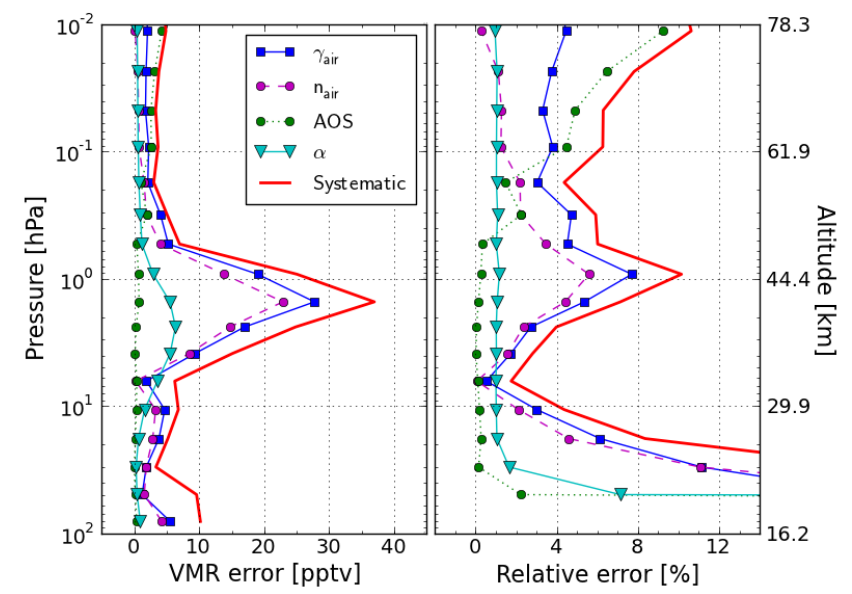

Fig. 8. Same as Fig. 4 except for the systematic error. The total systematic error and the errors from the main error sources are shown. Blue: $3 \%$ uncertainty in $\gamma_{\text {air }}$. Purple: $10 \%$ uncertainty in $n_{\text {air }}$. Green: $10 \%$ uncertainty in the width of the AOS response function. Cyan: $20 \%$ uncertainty in $\alpha$. Red: total systematic error.

\subsubsection{Summary of systematic error}

Figure 8 shows $\boldsymbol{E}_{\text {systematic }}$ and its main components such as the errors due to the uncertainties in the $\gamma_{\text {air }}$ and $n_{\text {air }}$ of the $\mathrm{ClO}$ transition, the width of the AOS response function and $\alpha . \boldsymbol{E}_{\text {systematic }}$ is smaller than $10 \mathrm{pptv}$ at all pressures except for around $1 \mathrm{hPa}$, where the ClO VMR is increased. The uncertainties in $\gamma_{\text {air }}$ and $n_{\text {air }}$ are dominant in the region of pressure larger than $0.1 \mathrm{hPa}$. The error from the AOS response function is the largest followed by that from $\gamma_{\text {air }}$ at the pressures less than $0.1 \mathrm{hPa}$. The gain-compression parameter $(\alpha)$ has the largest of among the calibration parameters, but the error from $\alpha$ is smaller than the other errors in Fig. 8.

There is a peak at about $2 \mathrm{hPa}(40 \mathrm{~km})$ in the VMR error. This may be because of the assumed $\mathrm{ClO}$ VMR profile, i.e. the a priori profile $\boldsymbol{x}_{\mathrm{a}}$, which has VMR maximum at $40 \mathrm{~km}$. The errors due to the uncertainties in $\gamma_{\text {air }}$ and $n_{\text {air }}$, which are the large error sources in $\boldsymbol{E}_{\text {systematic }}$, depend on the retrieved VMR value. The value of $\boldsymbol{x}_{\mathrm{a}}$ decreases rapidly at the pressures less than $2 \mathrm{hPa}(40 \mathrm{~km})$, and the peak of the relative error is located at about $1 \mathrm{hPa}(45 \mathrm{~km})$.

Overall, the error due to $\gamma_{\text {air }}$ makes the largest contribution to $\boldsymbol{E}_{\text {systematic }}$. The uncertainties in laboratory measurements of $\gamma_{\text {air }}$ are difficult to be reduced because of experimental systematic errors such as errors in measurements of pressure, difficulties of maintaining stable temperature conditions during measurements (Sato et al., 2010), and contaminations with undesirable species (Oh and Cohen, 1994), for example. Moreover, no theoretical prediction of $\gamma_{\text {air }}$ has yet been completely established. We concluded that the uncertainty in $\gamma_{\text {air }}$ was one of the largest error sources in the $\mathrm{ClO}$ retrieval.

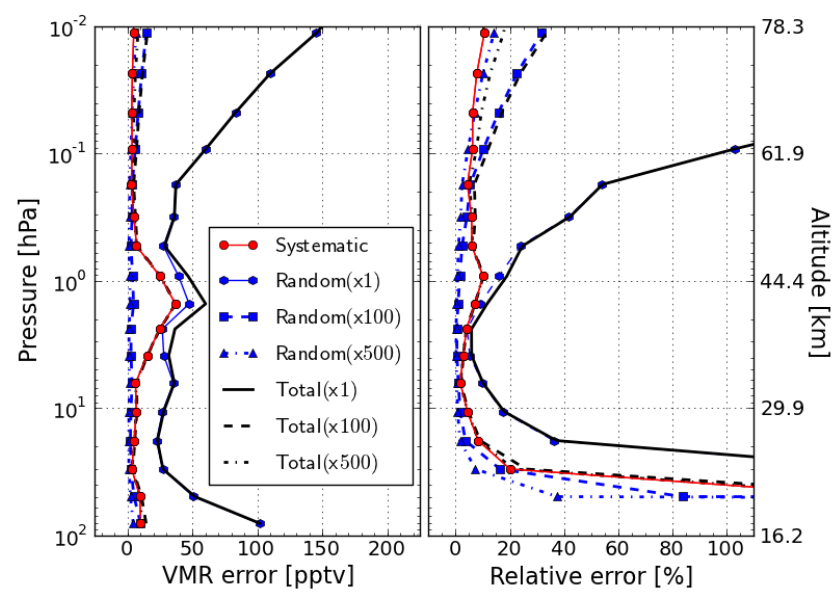

Fig. 9. Same as Fig. 4 except for the total error. Total error in the ClO retrieval for averaging of $N$ profiles $(N=1,100$ and 500). Red: systematic error. Blue: random error when averaging $N$ profiles. Black: total error when averaging $N$ profiles.

\subsection{Total error}

Figure 9 shows $\boldsymbol{E}_{\text {random }}, \boldsymbol{E}_{\text {systematic }}$ and $\boldsymbol{E}_{\text {total }}$ for a singlescan observation and averaging of $N(=100,500)$ profiles. $\boldsymbol{E}_{\text {random }}$ is larger than $\boldsymbol{E}_{\text {systematic }}$ for a single-scan observation, and is dominant in $\boldsymbol{E}_{\text {total }}$ at all pressures. Averaging 100 profiles, $\boldsymbol{E}_{\text {random }}(100)$ is less than 10 pptv $(10 \%)$ at

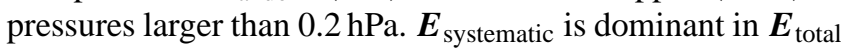
(100) in this pressure region. $\boldsymbol{E}_{\text {random }}(100)$ is still as large as $10-20 \mathrm{pptv}$ in the pressure region smaller than $0.2 \mathrm{hPa}$. When 500 profiles are averaged, $\boldsymbol{E}_{\text {random }}(500)$ is less than $10 \mathrm{pptv}$ $(20 \%)$ at all pressures.

We compared the errors in the CIO VMR of the SMILES L2r (v2.1.5) estimated in this work, those in UARS/MLS (v5) by Livesey et al. (2003), Aura/MLS (v3-3) by Livesey et al. (2011), and Odin/SMR (Chalmers v2.1) by Urban et al. (2006). The systematic errors, the random errors $(1-\sigma)$ for a single-scan observation and the vertical resolutions at 0.5 , 2 and $10 \mathrm{hPa}$ are summarized in Table 3. The systematic errors of SMILES, UARS/MLS and Aura/MLS are of the same order 10-50 pptv. The random errors of SMILES are about a tenth of those with the other instruments because of the lownoise spectra observed using the SIS mixers. The vertical resolutions of SMILES are comparable to those of Aura/MLS and Odin/SMR.

\section{ClO diurnal variations}

\subsection{Evaluation of SMILES ClO diurnal variations}

Figure 10 shows the diurnal variations in SMILES zonal mean $\mathrm{ClO}$ for mid-latitude $\left(40^{\circ} \mathrm{N}-50^{\circ} \mathrm{N}\right)$ and equatorial $\left(5^{\circ} \mathrm{S}-5^{\circ} \mathrm{N}\right)$ regions at the pressures of $10 \mathrm{hPa}(30 \mathrm{~km})$, $4.6 \mathrm{hPa}(35 \mathrm{~km}), 2.1 \mathrm{hPa}(41 \mathrm{~km}), 1 \mathrm{hPa}(47 \mathrm{~km}), 0.46 \mathrm{hPa}$ 
Table 3. Summary of the errors $(1-\sigma)$ for a single-scan observation of ClO products observed by SMILES, UARS/MLS, Aura/MLS and Odin/SMR. Systematic error (SE), random error (RE) and vertical resolution (VR) for these instruments are listed.

\begin{tabular}{|c|c|c|c|c|c|c|c|c|c|c|c|c|}
\hline \multirow[b]{2}{*}{$\begin{array}{l}\text { Pressure } \\
\text { (Altitude) }\end{array}$} & \multicolumn{3}{|c|}{ SMILES L2r (v2.1.5) $)^{1}$} & \multicolumn{3}{|c|}{ UARS/MLS (v5) ${ }^{2}$} & \multicolumn{2}{|c|}{ Aura/MLS (v3-3) } & \multicolumn{4}{|c|}{ Odin/SMR (Chalmers v2.1) } \\
\hline & $\begin{array}{c}\text { SE } \\
\text { (pptv) }\end{array}$ & $\begin{array}{c}\mathrm{RE} \\
\text { (pptv) }\end{array}$ & $\begin{array}{l}\text { VR } \\
(\mathrm{km})\end{array}$ & $\begin{array}{c}\text { SE } \\
\text { (pptv) }\end{array}$ & $\begin{array}{c}\mathrm{RE} \\
\text { (pptv) }\end{array}$ & $\begin{array}{l}\text { VR } \\
(\mathrm{km})\end{array}$ & $\begin{array}{c}\mathrm{SE} \\
(\mathrm{pptv})\end{array}$ & $\begin{array}{c}\mathrm{RE} \\
\text { (pptv) }\end{array}$ & $\begin{array}{l}\text { VR } \\
(\mathrm{km})\end{array}$ & $\begin{array}{c}\text { SE } \\
\text { (pptv) }\end{array}$ & $\begin{array}{c}\mathrm{RE} \\
\text { (pptv) }\end{array}$ & $\begin{array}{c}\text { VR } \\
(\mathrm{km})\end{array}$ \\
\hline $0.5 \mathrm{hPa}(50 \mathrm{~km})$ & 10 & 30 & 5.5 & - & - & - & - & - & - & $\leq 100$ & $\leq 150$ & $2.5-3$ \\
\hline $2 \mathrm{hPa}(40 \mathrm{~km})$ & 30 & 40 & 4 & 60 & 400 & 6 & 25 & 100 & $3.5-4.5$ & $\leq 100$ & $\leq 150$ & $2.5-3$ \\
\hline $10 \mathrm{hPa}(30 \mathrm{~km})$ & 10 & 30 & 4 & 30 & 400 & 4 & 20 & 100 & $3.5-4.5$ & $\leq 100$ & $\leq 150$ & $2.5-3$ \\
\hline
\end{tabular}

${ }^{1}$ This work. ${ }^{2}$ See Table 9 in Livesey et al. (2003). ${ }^{3}$ See Table 3.5.1 in Livesey et al. (2011). ${ }^{4}$ See Table 1 in Urban et al. (2006).

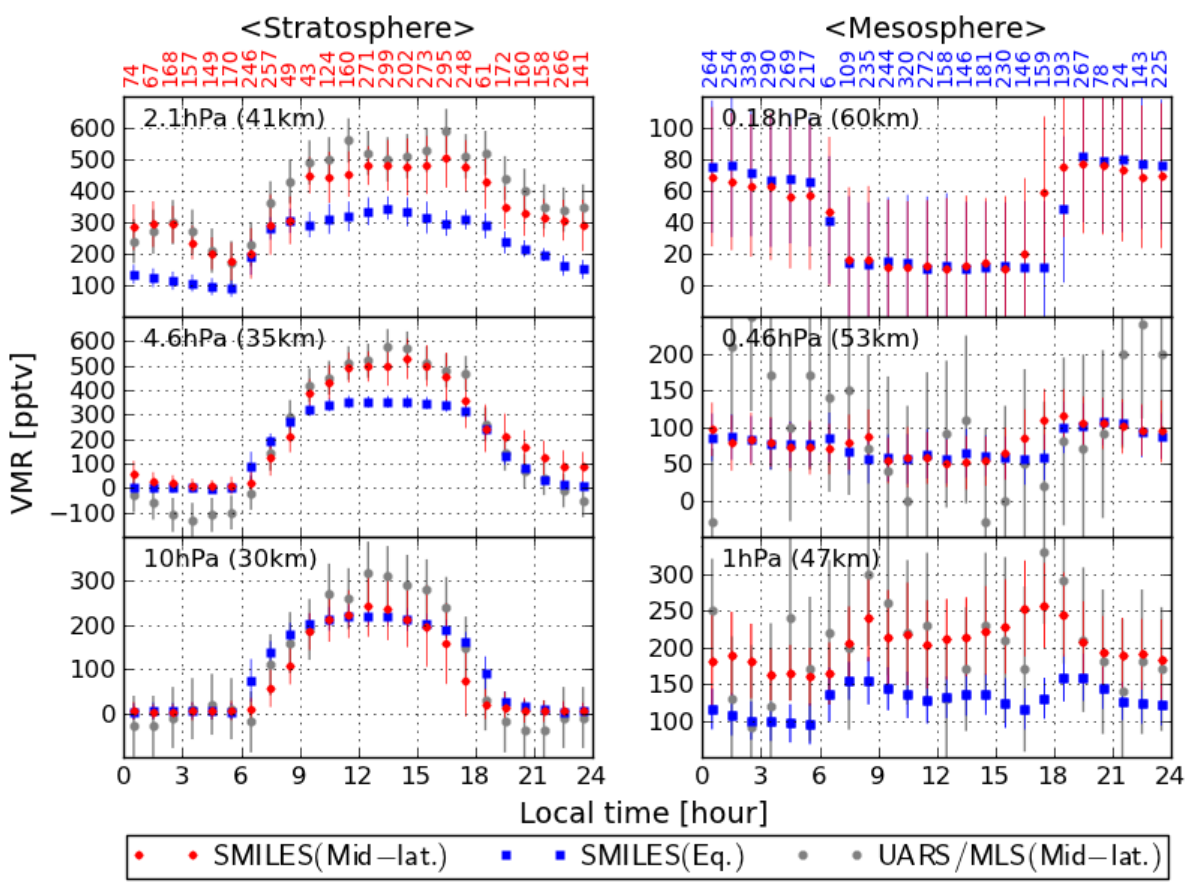

Fig. 10. ClO diurnal variations observed by SMILES and UARS/MLS at pressures of $0.18,0.46,1,2.1,4.6$ and $10 \mathrm{hPa}$ for zonal mean. Red: SMILES at $40^{\circ} \mathrm{N}-50^{\circ} \mathrm{N}$. Blue: SMILES at $5^{\circ} \mathrm{S}-5^{\circ} \mathrm{N}$. Gray: UARS/MLS at $40^{\circ} \mathrm{N}-50^{\circ} \mathrm{N}$. The data are averaged within a local time bin of $1-\mathrm{h}$ intervals. The vertical error bars represent $1-\sigma$ standard deviations. The numbers of profiles averaged at each local time for the SMILES observations at $40^{\circ} \mathrm{N}-50^{\circ} \mathrm{N}$ and $5^{\circ} \mathrm{S}-5^{\circ} \mathrm{N}$ are indicated at the top of the left and right panels, respectively. The vertical grids for SMILES were adjusted to the UARS/MLS grids with linear interpolation. The SMILES data are taken for the observation period from January to February 2010, while UARS/MLS data are taken by averaging February data for the seven years from 1991 to 1997. The UARS/MLS data are taken from Fig. 1 in Ricaud et al. (2000). Arbitrary offsets are respectively added to the UARS/MLS data of 100, 200, 400, 200 and $100 \mathrm{pptv}$ at $0.46,1,2.1,4.6$ and $10 \mathrm{hPa}$, since the UARS/MLS data have a negative bias.

$(53 \mathrm{~km})$ and $0.18 \mathrm{hPa}(60 \mathrm{~km})$. Two months of data from the SMILES observations were averaged from JanuaryFebruary in 2010. Criteria for data selection were measurement response $>0.8$ (Eq. 19) and $\chi^{2}<1$ (Eq. 13). The numbers of the SMILES profiles averaged for each $1 \mathrm{~h}$ local time bin were 43-299 and 6-339 for the mid-latitude region and the equatorial region, respectively. The UARS/MLS observations (Ricaud et al., 2000) were compared with the SMILES observations in Fig. 10. The UARS/MLS ClO data for February at the mid-latitude were averaged over seven years (from 1991 to 1997). Arbitrary offsets were respectively added as 100, 200, 400, 200 and 100 pptv at 0.46, 1,
2.1, 4.6 and $10 \mathrm{hPa}$ to the UARS/MLS ClO observations. The vertical error bars represent $1-\sigma$ standard deviations for both SMILES and UARS/MLS.

The nighttime CIO VMR values are near zero from 00:0006:00 (a.m.) in the middle stratosphere at $10 \mathrm{hPa}(30 \mathrm{~km})$ and $4.6 \mathrm{hPa}(35 \mathrm{~km})$. The standard deviations in these time and pressure region present an internal error in the SMILES CIO observations, and not natural variations. The standard deviations are about 20-30 pptv and consistent with the random error of 30 pptv estimated by the error analysis. This indicates that the error analysis results are realistic. 
Oct.-Nov. (2009)
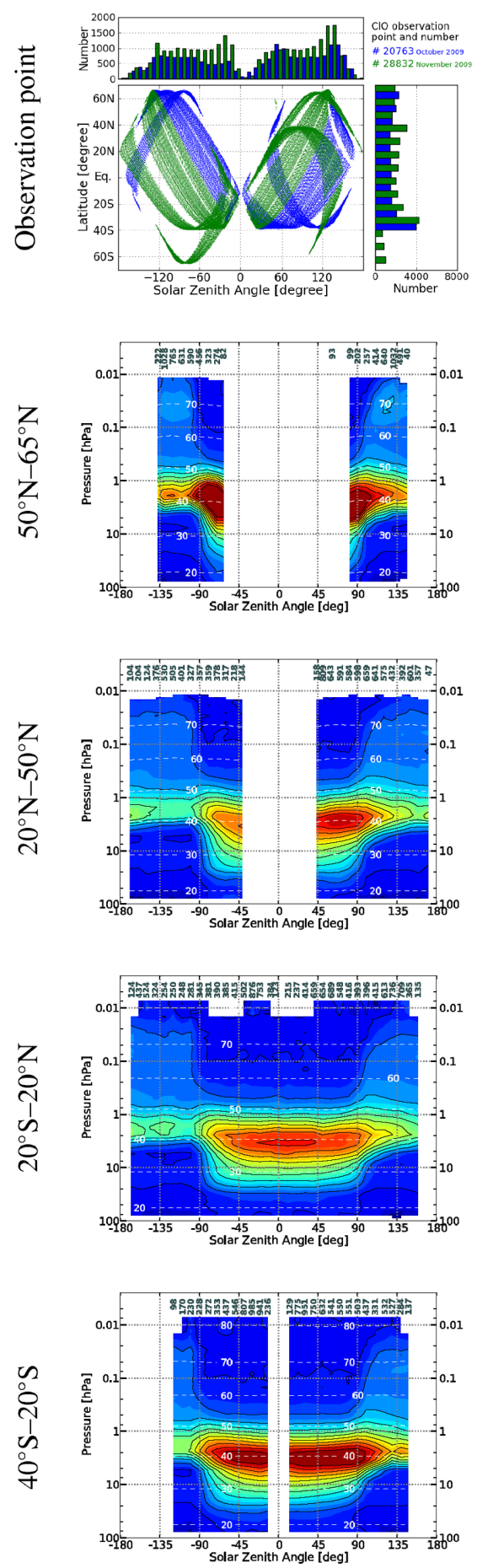

Jan.-Feb. (2010)
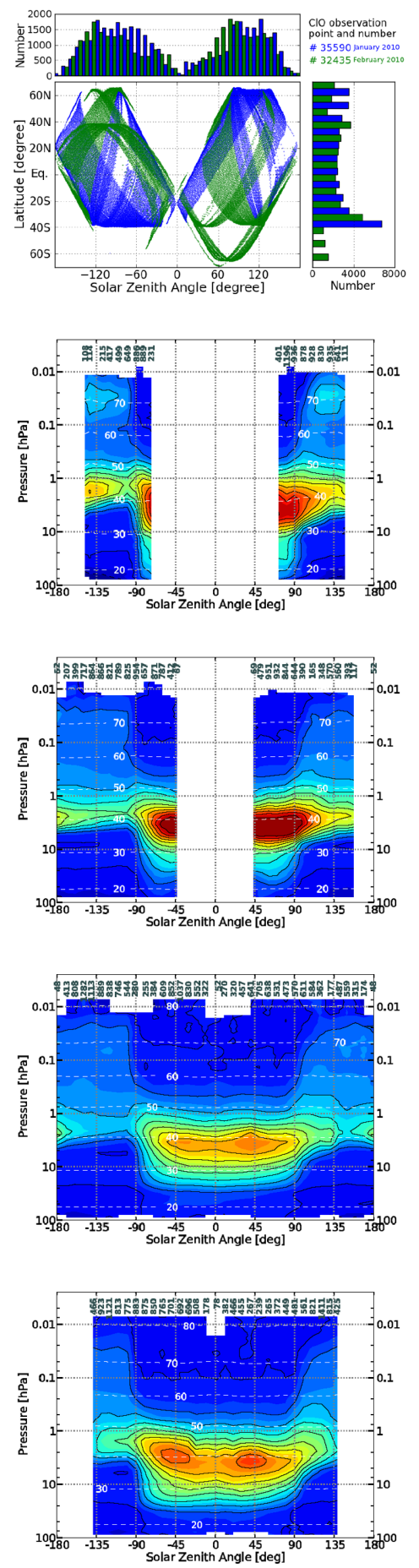

Mar.-Apr. (2010)
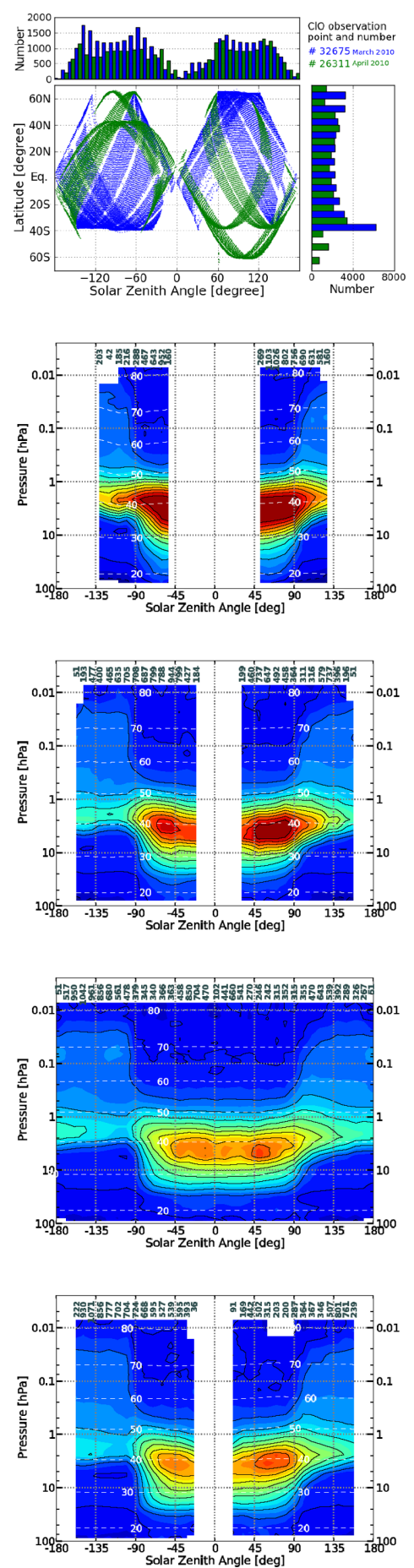

Fig. 11. Seasonal and latitudinal variations in the $\mathrm{ClO}$ diurnal variations as a function of SZA and pressure for October-November 2009, January-February 2010 and March-April 2010 and latitudes $\left(50^{\circ} \mathrm{N}-65^{\circ} \mathrm{N}, 20^{\circ} \mathrm{N}-50^{\circ} \mathrm{N}, 20^{\circ} \mathrm{S}-20^{\circ} \mathrm{N}\right.$ and $\left.40^{\circ} \mathrm{S}-20^{\circ} \mathrm{S}\right)$. The color contour levels are separated by $25 \mathrm{pptv}$. The altitude is represented by the white dotted line. The numbers of averaged profiles in SZA bins of $10^{\circ}$ are indicated at the top of each panel. Only retrieved VMR values that satisfy $\chi^{2}<1$ and $m>0.8$ are used. The observation points in the top row are represented by dots of different colors for each month. The numbers of scans in an SZA bin of $10^{\circ}$ and a latitude bin of $10^{\circ}$ are represented by bars at the top and above and to the right. The total number of scans is given at the upper right. 
The amplitudes of the observed $\mathrm{ClO}$ diurnal variations of 100-300 pptv are significantly larger than the random error of $30 \mathrm{pptv}$ for 100 averaged profiles and the systematic error for SMILES of 10-30 pptv at all pressures.

Moreover, the behaviors of the diurnal variations in the ClO VMR for the stratosphere deduced from the SMILES and the UARS/MLS observations gave a good agreement within their 1- $\sigma$ standard deviations as plotted in Fig. 10, although the artificial biases were added to the UARS/MLS data.

\subsection{Global ClO diurnal variations}

Global diurnal variations of $\mathrm{ClO}$ are shown in Fig. 11 as a function of solar zenith angle (SZA) over the SMILES observation period from 12 October 2009 to 21 April 2010 in the stratosphere and the mesosphere for the zonal means of $40^{\circ} \mathrm{S}-20^{\circ} \mathrm{S}, 20^{\circ} \mathrm{S}-20^{\circ} \mathrm{N}, 20^{\circ} \mathrm{N}-50^{\circ} \mathrm{N}$ and $50^{\circ} \mathrm{N}-65^{\circ} \mathrm{N}$. Note that we define the SZA with a range of $-180^{\circ}$ to $+180^{\circ}$ in this paper. A negative SZA is used for the a.m. condition and a positive one is for p.m.. There were no SMILES ClO observations in December 2009, because only Bands A and B were used in that month. The contour intervals in Fig. 11 are $25 \mathrm{pptv}$, which is the total error estimated for an average of 100 profiles. In Fig. 11, each SZA bin of $10^{\circ}$ was calculated by averaging more than 100 profiles except for the bins where there were fewer observations because of the orbit of the SMILES observation. The coverage of the SMILES observations was not homogeneous in terms of SZA and location, as indicated by the top panels of Fig. 11.

The $\mathrm{ClO}$ VMR in the stratosphere was enhanced during the day and fell to near zero at night. This is consistent with the diurnal variations in ClO VMR observed by UARS/MLS (Fig. 10). The ClO VMR in the afternoon was larger than that in the morning. The lower stratospheric $\mathrm{ClO}$ enhancement was strongest in the polar region and faded toward the equatorial region.

It seems that the stratospheric (around $40 \mathrm{~km}$ ) $\mathrm{ClO}$ decreases as a dent near $\mathrm{SZA}=0^{\circ}$; we can most clearly see it in the panel for $40^{\circ} \mathrm{S}-20^{\circ} \mathrm{S}$ from January-February. The dent structures are also observed at latitudes and seasons of $40^{\circ} \mathrm{S}-20^{\circ} \mathrm{S}$ from March-April, $20^{\circ} \mathrm{S}-20^{\circ} \mathrm{N}$ from JanuaryFebruary and March-April, and $20^{\circ} \mathrm{N}-50^{\circ} \mathrm{N}$ from MarchApril. Since there are only a few data near $\mathrm{SZA}=0^{\circ}$ and these are concentrated at specific narrow latitude ranges shown in the top of Fig. 11, further careful analyses are required to understand what the causes of these apparent dent structures are. One possible interpretation of the dent structures could be suggested via a coupling of $\mathrm{ClO}$ abundance with the diurnal behavior of atomic $\mathrm{O}$ radicals and $\mathrm{O}_{3}$. The amount of stratospheric $\mathrm{ClO}$ is controlled by the following reactions during daytime:

$$
\begin{aligned}
& \mathrm{ClO}+\mathrm{O} \rightarrow \mathrm{Cl}+\mathrm{O}_{2}, \\
& \mathrm{Cl}+\mathrm{O}_{3} \rightarrow \mathrm{ClO}+\mathrm{O}_{2} .
\end{aligned}
$$

$\mathrm{ClO}$ photolysis also occurs but the contribution of this path is much smaller than that of Reaction (R1) and can be ignored. There is a peak amount of O VMR near SZA $=0^{\circ}$ in the stratosphere (M. Khosravi, personal communication, 2010). The $\mathrm{ClO}$ dent structures are produced if $[\mathrm{O}] /\left[\mathrm{O}_{3}\right] \gg 1$ is satisfied near $\mathrm{SZA}=0^{\circ}$.

The $\mathrm{ClO}$ in the mesosphere is enhanced during the night. This feature has been predicted by several models and precisely observed for the first time by SMILES. An event with a higher mesospheric $\mathrm{ClO}$ VMR is observed around $70 \mathrm{~km}$ in the near-polar region of $50^{\circ} \mathrm{N}-65^{\circ} \mathrm{N}$ at nighttime $\left(\mathrm{SZA}= \pm 130^{\circ}\right)$ as shown in Fig. 11. The " $\mathrm{ClO}$ mesospheric enhancement" that is located close to the tertiary $\mathrm{O}_{3}$ maximum (Marsh and Smith, 1995) seems to start from OctoberNovember 2009 and fades from March-April 2010. ClO is enhanced through the Reaction (R2) because of the $\mathrm{O}_{3}$ enhancement. The amplitude of the $\mathrm{ClO}$ enhancement is about $100 \mathrm{ppbv}$. The profile was produced by averaging more than 100 profiles in SZA bins of $10^{\circ}$. This amplitude is three times larger than the estimated total error of 20-30 pptv at $70-80 \mathrm{~km}$ and therefore significant.

\section{Conclusions}

SMILES observed the stratospheric and mesospheric $\mathrm{ClO}$ at latitudes between $38^{\circ} \mathrm{S}-65^{\circ} \mathrm{N}$. We quantitatively investigated the errors in the $\mathrm{ClO}$ L2r product version 2.1.5 including the errors due to spectrum noise, smoothing, the uncertainties in the radiative transfer calculations and the instrument functions, and the inaccuracies in the spectrum calibrations. The total error for a single-scan observation was less than about $50 \mathrm{pptv}$ at the pressures between 0.1 and $60 \mathrm{hPa}$. The total error was decreased to $10-30 \mathrm{pptv}$ (about $10 \%$ ) at the pressures between $0.01 \mathrm{hPa}$ (about $80 \mathrm{~km}$ ) and $100 \mathrm{hPa}$ (about $16 \mathrm{~km}$ ) with the averaging of $100-500$ profiles. The largest effect on the systematic error was from the air-broadening coefficient, $\gamma_{\text {air }}$, which contributed up to $8 \%$ to the total systematic error of $10 \%$ at the pressure of $2 \mathrm{hPa}$ (about $42 \mathrm{~km}$ ).

We have presented the SMILES global ClO diurnal variations in the stratosphere and the mesosphere. The diurnal variations of the stratospheric $\mathrm{ClO}$ showed good agreements with those of UARS/MLS. The behavior of the diurnal variation in $\mathrm{ClO}$ was consistent with the known diurnal chemistry. The global diurnal variations of $\mathrm{ClO}$ from the stratopause well into the mesosphere, to altitudes of more than $70 \mathrm{~km}$, were obtained for the first time by using the SMILES observations. Nighttime enhancement of $\mathrm{ClO}$ at $0.02 \mathrm{hPa}$ (about $70 \mathrm{~km}$ ) was detected at the high northern latitudes from January-February 2010. The quantitative error analysis provided here indicated that these $\mathrm{ClO}$ features were atmospheric in nature. 
Acknowledgements. The JEM/SMILES mission is a joint project of the Japan Aerospace Exploration Agency (JAXA) and the National Institute of Information and Communications Technology (NICT). The authors wish to acknowledge the contributions made by M. Shiotani (Kyoto University), M. Suzuki (ISAS/JAXA), and our colleagues at JAXA and NICT for managing and supporting the SMILES mission. The authors also thank K. Muranaga (Systems Engineering Consultants Co., Ltd.) and J. Möller (Molflow Co., Ltd.) for supporting data processing in the Level-2 research product. Further, the authors thank K. Suzuki for providing technical supports. In addition, TOS thanks H. Kanamori and N. Yoshida (Tokyo Institute of Technology) for their kind supports. TOS is supported by a Grant in Aid for Research Fellowship for Young Scientists DC1 (No. 23-9766) from the Japan Society for the Promotion of Science, and the Global COE program "Earth to Earths" of the Ministry of Education, Culture, Sports, Science and Technology, Japan. YK is supported by a Funding Program for Next Generation World-Leading Researchers (NEXT Program) (No. GR101).

\section{Edited by: T. von Clarmann}

\section{References}

Baron, P., Ricaud, P., de La Noë, J., Eriksson, J. E. P., Merino, F., Ridal, M., and Murtagh, D. P.: Studies for the Odin sub-millimetre radiometer, II. Retrieval methodology, Can. J. Phys., 80, 341356, doi:10.1139/p01-150, 2002.

Baron, P., Mendrok, J., Kasai, Y., Ochiai, S., Seta, T., Sagi, K., Suzuki, K., Sagawa, H., and Urban, J.: AMATERAU: Model for atmospheric terahertz radiation analysis and simulation, J. Natl. Inst. Inform. Commun. Technol., 55, 109-121, 2008.

Baron, P., Urban, J., Sagawa, H., Möller, J., Murtagh, D. P., Mendrok, J., Dupuy, E., Sato, T. O., Ochiai, S., Suzuki, K., Manabe, T., Nishibori, T., Kikuchi, K., Sato, R., Takayanagi, M., Murayama, Y., Shiotani, M., and Kasai, Y.: The Level 2 research product algorithms for the Superconducting Submillimeter-Wave Limb-Emission Sounder (SMILES), Atmos. Meas. Tech., 4, 2105-2124, doi:10.5194/amt-4-2105-2011, 2011.

Boissoles, J., Boulet, C., Tipping, R. H., Brown, A., and Ma, Q.: Theoretical calculation of the translation-rotation collisioninduced absorption in $\mathrm{N}_{2}-\mathrm{N}_{2}, \mathrm{O}_{2}-\mathrm{O}_{2}$, and $\mathrm{N}_{2}-\mathrm{O}_{2}$ pairs, J. Quant. Spectrosc. Ra., 82, 505-516, doi:10.1016/S00224073(03)00174-2, 2003.

Cazzoli, G. and Puzzarini, C.: Hyperfine structure of the $J=1 \leftarrow 0$ transition of $\mathrm{H}^{35} \mathrm{Cl}$ and $\mathrm{H}^{37} \mathrm{Cl}$ : improved ground state parameters, J. Mol. Spectrosc., 226, 161-168, 2004.

Drouin, B. J.: Submillimeter measurements of $\mathrm{N}_{2}$ and air broadening of hypochlorous acid, J. Quant. Spectrosc. Ra., 103, 558-564, doi:10.1016/j.jqsrt.2006.07.007, 2007.

Drouin, B. J. and Gamache, R. R.: Temperature dependent air-broadened linewidths of ozone rotational transitions, J. Mol. Spectrosc., 251, 194-202, doi:10.1016/j.jms.2008.02.016, 2008.

Hedin, A. E.: Extension of the MSIS thermosphere model into the middle and lower atmosphere, J. Geophys. Res., 96, 1159-1172, doi:10.1029/90JA02125, 1991.
Hoshina, H., Seta, T., Iwamoto, T., Hosako, I., Otani, C., and Kasai, Y.: Precise measurement of pressure broadening parameters for water vapor with a terahertz time-domain spectrometer, J. Quant. Spectrosc. Ra., 109, 2303-2314, doi:10.1016/j.jqsrt.2008.03.005, 2008.

Kikuchi, K., Nishibori, T., Ochiai, S., Ozeki, H., Irimajiri, Y., Kasai, Y., Koike, M., Manabe, T., Mizukoshi, K., Murayama, Y., Nagahama, T., Sano, T., Sato, R., Seta, M., Takahashi, C., Takayanagi, M., Masuko, H., Inatani, J., Suzuki, M., and Shiotani, M.: Overview and early results of the Superconducting Submillimeter-Wave Limb-Emission Sounder (SMILES), J. Geophys. Res.-Atmos., 115, D23306, doi:10.1029/2010JD014379, 2010.

Livesey, N. J., Read, W. G., Froidevaux, L., Waters, J. W., Santee, M. L., Pumphrey, H. C., Wu, D. L., Shippony, Z., and Jarnot, R. F.: The UARS Microwave Limb Sounder version 5 data set: theory, characterization, and validation, J. Geophys. Res.-Atmos., 108, 4378, doi:10.1029/2002JD002273, 2003.

Livesey, N. J., Read, W. G., Froidevaux, L., Lambert, A., Manney, G. L., Pumphrey, H. C., Santee, M. L., Schwartz, M. J., Wang, S., Cofield, R. E., Cuddy, D. T., Fuller, R. A., Jarnot, R. F., Jiang, J. H., Knosp, B. W., Stek, P. C., Wagner, P. A., and Wu, D. L.: Version 3.3 Level 2 data quality and description document, Tech. Rep. JPL D-33509, Jet Propulsion Laboratory, available at: http://mls.jpl.nasa.gov/data/datadocs.php (last access: 29 June 2012), 2011.

Manabe, T., Inatani, J., Murk, A., Wylde, R., Seta, M., and Martin, D.: A new configuration of polarization-rotating dual-beam interferometer for space use, IEEE T. Microw. Theory, 51, 16961704, doi:10.1109/TMTT.2003.812567, 2003.

Manabe, T., Nishibori, T., Mizukoshi, K., Otsubo, F., Ochiai, S., and Ohmine, H.: Measurement of the offset-Cassegrain antenna of JEM/SMILES using a near-field phase-retrieval method in the $640 \mathrm{GHz}$ Band, IEEE T. Antenn. Propag., 60, 3971-3975, doi:10.1109/TAP.2012.2201080, 2012.

Manney, G. L., Santee, M. L., Rex, M., Livesey, N. J., Pitts, M. C., Veefkind, P., Nash, E. R., Wohltmann, I., Lehmann, R., Froidevaux, L., Poole, L. R., Schoeberl, M. R., Haffner, D. P., Davies, J., Dorokhov, V., Gernandt, H., Johnson, B., Kivi, R., Kyrö, E., Larsen, N., Levelt, P. F., Makshtas, A., McElroy, C. T., Nakajima, H. P. M. C., Tarasick, D. W., Gathen, P., Walker, K. A., and Zinoviev, N. S.: Unprecedented Arctic ozone loss in 2011, Nature, 478, 469-475, doi:10.1038/nature10556, 2011.

Markov, V. N. and Krupnov, A. F.: Measurements of the pressure shift of the $1_{10}-1_{01}$ water line at $556 \mathrm{GHz}$ produced by mixtures of gases, J. Mol. Spectrosc., 172, 211-214, 1995.

Marsh, D. and Smith, A.: The existence of a tertiary ozone maximum in the high-latitude middle mesosphere, Geophys. Res. Lett., 28, 4531-4534, 2001.

Masuko, H., Shiotani, M., and SMILES mission team: JEM/SMILES Mission Plan, version 2.1., Tech. Rep. NASDA/CRL, National Space Development Agency of Japan, and Communications Research Laboratory, available at: http://smiles.nict.go.jp/Mission_Plan (last access: 29 June 2012), 2002. 
Mizobuchi, S., Kikuchi, K., Ochiai, S., Nishibori, T., Sano, T., Tamaki, K., and Ozeki, H.: In-orbit measurement of the AOS (Acousto-Optical Spectrometer) response using frequency comb signals, IEEE J. Sel. Topics Appl. Earth Obs. Remote Sens., 5, 977-983 2012.

Mizoguchi, A., Yagi, T., Kondo, K., Sato, T. O., and Kanamori, H.: Submillimeter-wave measurements of $\mathrm{N}_{2}$ and $\mathrm{O}_{2}$ pressure broadening for $\mathrm{HO}_{2}$ radical generated by $\mathrm{Hg}-$ photosensitized reaction, J. Quant. Spectrosc. Ra., 113, 279-285, doi:10.1016/j.jqsrt.2011.11.009, 2012.

Murtagh, D., Frisk, U., Merino, F., Ridal, M., Jonsson, A., Stegman, J., Witt, G., Eriksson, P., Jiménez, C., Megie, G., de La Noë, J., Ricaud, P., Baron, P., Pardo, J. R., Hauchcorne, A., Llewellyn, E. J., Degenstein, D. A., Gattinger, R. L., Lloyd, N. D., Evans, W. F. J., McDade, I. C., Haley, C. S., Sioris, C., von Savigny, C., Solheim, B. H., McConnell, J. C., Strong, K., Richardson, E. H., Leppelmeier, G. W., Kyrölä, E., Auvinen, H., and Oikarinen, L.: An overview of the Odin atmospheric mission, Can. J. Phys., 80, 309-318, doi:10.1139/p01-157, 2002.

Ochiai, S., Nishibori, T., Ozeki, H., Kikuchi, K., and Manabe, T.: Superconducting submillimeter-wave limb-emission sounder on the international space station I: radiometric and spectral calibration and data processing, J. Natl. Inst. Inform. Commun. Technol., 55, 83-95, 2008.

Ochiai, S., Kikuchi, K., Nishibori, T., and Manabe, T.: Gain nonlinearity calibration of submillimeter radiometer for JEM/SMILES, IEEE J. Sel. Topics Appl. Earth Obs. Remote Sens. 5, 962-969, 2012a.

Ochiai, S., Nishibori, T., Kikuchi, K., Mizobuchi, S., Manabe, T., Mitsuda, C., Baron, P., and Ueno, S.: Tangent height accuracy of Superconducting Submillimeter-wave Limb-emission Sounder (SMILES) on International Space Station (ISS), Proc. IEEE Int. Geosci. Remote Sens. Symp., 1290-1293, 2012b.

Ochiai, S., Kikuchi, K., Nishibori, T., Manabe, T., Ozeki, H., Mizobuchi, S., and Irimajiri, Y.: Receiver performance of Superconducting Submillimeter-Wave Limb-Emission Sounder (SMILES) on the International Space Station, IEEE Trans. Geosci. Remote Sens., doi:10.1109/TGRS.2012.2227758, in press, 2012c.

Oh, J. and Cohen, E. A.: Pressure broadening of $\mathrm{ClO}$ by $\mathrm{N}_{2}$ and $\mathrm{O}_{2}$ near 204 and $649 \mathrm{GHz}$ and new frequency measurements between 632 and 725 GHz, J. Quant. Spectrosc. Ra., 52, 151-156, doi:10.1016/0022-4073(94)90004-3, 1994.

Pardo, J. R., Serabyn, E., and Cernicharo, J.: Submillimeter atmospheric transmission measurements on Mauna Kea during extremely dry El Niño conditions: implications for breadband opacity contributions, J. Quant. Spectrosc. Ra., 68, 419-433, 2001.

Perrin, A., Puzzarini, C., Colmont, J. M., Verdes, C., Wlodarczak, G., Cazzoli, G., Buehler, S., Flaud, J. M., and Demaison, J.: Molecular line parameters for the "MASTER" (millimeter wave acquisitions for stratosphere/troposphere exchange research) database, J. Atmos. Chem., 51, 161-205, 2005.

Pickett, H. M., Poynter, R. L., Cohen, E. A., Delitsky, M. L., Pearson, J. C., and Müller, H. S. P.: Submillimeter, millimeter and microwave spectral line catalog, J. Quant. Spectrosc. Ra., 60, 883-890, doi:10.1016/S0022-4073(98)00091-0, 1998.
Ricaud, P., Chipperfield, M. P., Waters, J. W., Russell III, J. M., and Roche, A. E.: Temporal evolution of chlorine monoxide in the middle stratosphere, J. Geophys. Res., 105, 4459-4470, doi:10.1029/1999JD900995, 2000.

Rienecker, M. M., Suarez, M. J., Todling, R., Bacmeister, J., Takacs, L., Liu, H.-C., Gu, W., Sienkiewicz, M., Koster, R. D., Gelaro, R., Stajner, I., and Nielsen, J. E.: The GEOS-5 Data Assimilation System - Documentation of Versions 5.0.1, 5.1.0, and 5.2.0, Tech. Rep. NASA/TM-2008-104606, vol. 27, National Aeronautics and Space Administration, available online: http://mls.jpl. nasa.gov/data/datadocs.php (last access: 29 June 2012), 2008.

Rodgers, C. D.: Inverse Methods for Atmospheric Sounding: Theory and Practice, Series on Atmospheric, Oceanic and Planetary Physics, vol. 2, World Scientific, Singapore, 3605-3609, 2000.

Rothman, L. S., Gordon, I. E., Barbe, A., Benner, D. C., Bernath, P. F., Birk, M., Boudon, V., Brown, L. R., Campargue, A., Champion, J.-P., Chance, K., Coudert, L. H., Dana, V., Devi, V. M., Fally, S., Flaud, J.-M., Gamache, R. R., Goldman, A., Jacquemart, D., Kleiner, I., Lacome, N., Lafferty, W. J., Mandin, J.-Y., Massie, S. T., Mikhailenko, S. N., Miller, C. E., Moazzen-Ahmadi, N., Naumenko, O. V., Nikitin, A. V., Orphal, J., Perevalov, V. I., Perrin, A., Predoi-Cross, A., Rinsland, C. P., Rotger, M., Šimečková, M., Smith, M. A. H., Sung, K., Tashkun, S. A., Tennyson, J., Toth, R. A., Vandaele, A. C., and Vander Auwera, J.: The HITRAN 2008 molecular spectroscopic database, J. Quant. Spectrosc. Ra., 110, 533-572, doi:10.1016/j.jqsrt.2009.02.013, 2009.

Sato, T. O.: Line selection algorithm for atmospheric radiative transfer calculation, J. Spectrosc. Soc. Jpn., 59, 99-101, 2010.

Sato, T. O., Mizoguchi, A., Mendrok, J., Kanamori, H., and Kasai, Y:: Measurement of the pressure broadening coefficient of the $625 \mathrm{GHz}$ transition of $\mathrm{H}_{2} \mathrm{O}_{2}$ in the submillimeter-wave region, J. Quant. Spectrosc. Ra., 111, 821-825, doi:10.1016/j.jqsrt.2009.11.022, 2010.

Schreier, F. and Kohlert, D.: Optimized implementations of rational approximations - a case study on the Voigt and complex error function, Comput. Phys. Commun., 179, 457-465, doi:10.1016/j.cpc.2008.04.012, 2008.

Schwartz, M. J., Lambert, A., Manney, G. L., Read, W. G., Livesey, N. J., Froidevaux, L., Ao, C. O., Bernath, P. F., Boone, C. D., Cofield, R. E., Daffer, W. H., Drouin, B. J., Fetzer, E. J., Fuller, R. A., Jarnot, R. F., Jiang, J. H., Jiang, Y. B., Knosp, B. W., Krüger, K., Li, J.-L. F., Mlynczak, M. G., Pawson, S., Russell, J. M., Santee, M. L., Snyder, W. V., Stek, P. C., Thurstans, R. P., Tompkins, A. M., Wagner, P. A., Walker, K. A., Waters, J. W., and $\mathrm{Wu}, \mathrm{D}$. L.: Validation of the aura microwave limb sounder temperature and geopotential height measurements, J. Geophys. Res.-Atmos., 113, D15S11, doi:10.1029/2007JD008783, 2008.

Urban, J., Baron, P., Lautié, N., Schneider, N., Dassas, K., Ricaud, P., and de La Noë, J.: Moliere (v5): a versatile forwardand inversion model for the millimeter and sub-millimeter wavelength range, J. Quant. Spectrosc. Ra., 83, 529-554, doi:10.1016/S0022-4073(03)00104-3, 2004. 
Urban, J., Murtagh, D., Lautié, N., Barret, B., Dupuy, É., de La Noë, J., Eriksson, P., Frisk, U., Jones, A., Le Flochmoën, É., Olberg, M., Piccolo, C., Ricaud, P., and Rösevall, J.: Odin/SMR Limb Observations of Trace Gases in the Polar Lower Stratosphere during 2004-2005, in: Atmospheric Science Conference, vol. 628 of ESA Special Publication, Frascati, Italy, 2006.

van Vleck, J. H. and Weisskopf, V. F.: On the shape of collision-broadened lines, Rev. Mod. Phys., 17, 227-236, doi:10.1103/RevModPhys.17.227, 1945.

Waters, J. W., Froidevaux, L., Read, W. G., Manney, G. L., Elson, L. S., Flower, D. A., Jarnot, R. F., and Harwood, R. S.: Stratospheric $\mathrm{ClO}$ and ozone from the microwave limb sounder on the upper atmosphere research satellite, Nature, 362, 597-602, doi:10.1038/362597a0, 1993.
Waters, J. W., Froidevaux, L., Harwood, R. S., Jarnot, R. F., Pickett, H. M., Read, W. G., Siegel, P. H., Cofield, R. E., Filipiak, M. J., Flower, D. A., Holden, J. R., Lau, G. K., Livesey, N. J., Manney, G. L., Pumphrey, H. C., Santee, M. L., Wu, D. L., Cuddy, D. T., Lay, R. R., Loo, M. S., Perun, V. S., Schwartz, M. J., Stek, P. C., Thurstans, R. P., Boyles, M. A., Chandra, K. M., Chavez, M. C., Chen, G.-S., Chudasama, B. V., Dodge, R., Fuller, R. A., Girard, M. A., Jiang, J. H., Jiang, Y., Knosp, B. W., Labelle, R. C., Lam, J. C., Lee, A. K., Miller, D., Oswald, J. E., Patel, N. C., Pukala, D. M., Quintero, O., Scaff, D. M., Vansnyder, W., Tope, M. C., Wagner, P. A., and Walch, M. J.: The Earth Observing System Microwave Limb Sounder (EOS MLS) on the aura satellite, IEEE T. Geosci. Remote, 44, 1075-1092, doi:10.1109/TGRS.2006.873771, 2006. 